\title{
Recent Insights Into SREBP as a Direct Mediator of Kidney Fibrosis via Lipid-Independent Pathways
}

\author{
Debra Dorotea ${ }^{1}$, Daisuke Koya ${ }^{2}$ and Hunjoo $\mathrm{Ha}^{1 *}$ \\ 1 Graduate School of Pharmaceutical Sciences, College of Pharmacy, Ewha Womans University, Seoul, South Korea, \\ ${ }^{2}$ Department of Internal Medicine, Kanazawa Medical University, Ishikawa, Japan
}

OPEN ACCESS

Edited by:

Md. Abdul Hye Khan,

Medical College of Wisconsin,

United States

Reviewed by:

Chunming Cheng,

The Ohio State University Comprehensive Cancer Center,

United States

Xiang Cheng,

The Ohio State University,

United States

${ }^{*}$ Correspondence:

Hunjoo $\mathrm{Ha}$

hha@ewha.ac.k

Specialty section:

This article was submitted to

Renal Pharmacology,

a section of the journal

Frontiers in Pharmacology

Received: 07 November 2019

Accepted: 24 February 2020

Published: 17 March 2020

Citation:

Dorotea $D$, Koya $D$ and $\mathrm{Ha} H$ (2020) Recent Insights Into SREBP as a Direct Mediator of Kidney Fibrosis

via Lipid-Independent Pathways.

Front. Pharmacol. 11:265.

doi: 10.3389/fphar.2020.00265
Sterol regulatory-element binding proteins (SREBPs) are classical regulators of cellular lipid metabolism in the kidney and other tissues. SREBPs are currently recognized as versatile transcription factors involved in a myriad of cellular processes. Meanwhile, SREBPs have been recognized to mediate lipotoxicity, contributing to the progression of kidney diseases. SREBP1 has been shown to bind to the promoter region of TGF $\beta$, a major pro-fibrotic signaling mechanism in the kidney. Conversely, TGF $\beta$ activates SREBP1 transcriptional activity suggesting a positive feedback loop of SREBP1 in TGF $\beta$ signaling. Public ChIP-seq data revealed numerous non-lipid transcriptional targets of SREBPs that plausibly play roles in progressive kidney disease and fibrosis. This review provides new insights into SREBP as a mediator of kidney fibrosis via lipid-independent pathways.

Keywords: SREBP, TGF $\beta$, lipotoxicity, renal lipid, kidney fibrosis

\section{INTRODUCTION}

Numerous studies have revealed the molecular mechanisms of sterol regulatory-element binding proteins (SREBPs) as transcription factors that critically regulate lipid homeostasis (Brown and Goldstein, 1997). The extended role of SREBPs within the last three decades has been attributed to its versatility in integrating multiple cellular signals to control, not only lipogenesis but also unexpected pathways that are important for diverse biological processes, such as endoplasmic reticulum (ER) stress, inflammation, autophagy, and apoptosis. Accordingly, SREBPs contribute to the pathogenesis of various diseases, such as diabetes mellitus, fatty liver disease, chronic kidney disease (CKD), neurodegenerative diseases, and cancers (Shimano and Sato, 2017).

CKD, a major public health problem in many countries (Webster et al., 2017), is defined by persistent urine abnormalities, structural abnormalities or impaired excretory renal function, which suggests a loss of functional nephrons (Romagnani et al., 2017). To date, renin-angiotensin system inhibitors are the mainstay of therapeutic options available to reduce albuminuria and slow the progression of CKD. However, these drugs show limitations in delaying the onset of kidney fibrosis, a common feature of end-stage kidney disease (Breyer and Susztak, 2016). Therefore, it remains interesting to explore the important target that mediates the disease progression, which can be further exploited to develop novel disease-modifying therapies.

Various factors, such as infiltrating immune cells, albuminuria, and glucosuria in diabetes, have been well recognized to activate proximal tubular epithelial cells, resulting in the secretion of proinflammatory and pro-fibrotic mediators that further promote interstitial inflammation and fibrosis development (Romagnani et al., 2017). Meanwhile, lipid accumulation in tubular cells has been associated with an increase in reactive oxygen species production, the loss of ATP production, apoptosis, and elevated inflammatory cytokines, which contribute to the development of tissue 
fibrosis (Simon and Hertig, 2015). In earlier studies, SREBP1 activation was shown to induce lipotoxicity that consequently extended SREBP-related pathology to include inflammation and fibrosis in the kidney (Sun et al., 2002). SREBP1 was further revealed to bind to the promoter region of transforming growth factor (TGF) $\beta$, a major pro-fibrotic signaling mechanism in the kidney (Uttarwar et al., 2012). Thus, SREBPs appear to mediate the progression of CKD via both lipid-dependent and -independent pathways. This review summarized the recent findings involving the TGF $\beta$ signaling pathway as a regulatory target of SREBP and predicts other putative target genes of SREBP in mediating kidney fibrosis.

\section{SREBPS AS CLASSIC MEDIATORS OF LIPOTOXICITY}

\section{The SREBP Family}

SREBPs are a family of membrane-bound transcription factors involved in lipid homeostasis. Three isoforms of SREBPs, SREBP1a, -1c, and -2, are encoded by two different genes. SREBP1a and $-1 \mathrm{c}$ originate from different promotors of sterol regulatory element-binding transcription factor (SREBF) 1 genes, whereas SREBP2 is derived from the SREBF2 gene (Goldstein et al., 2006). SREBP1a stimulates global lipid synthesis in proliferating cells, and SREBP1c plays a major role in the nutritional regulation of fatty acid and triglyceride (TG) synthesis in lipogenic organs, such as the liver. In contrast, SREBP2 ubiquitously regulates sterol synthesis in tissues (Shimano et al., 1997; Horton et al., 2002).

SREBPs are bHLH-LZ (basic-helix-loop-helix-leucine zipper) transcription factors, synthesized as inactive precursors bound to ER membranes. Each precursor is organized into three domains: (1) an NH2-terminal domain containing the transactivation domain, a region rich in serine and proline, and the bHLH-LZ region for DNA binding and dimerization; (2) two hydrophobic transmembrane segments projected into the ER lumen; and (3) a COOH-terminal domain (Goldstein et al., 2006; Figure 1).

\section{Proteolytic Activation of SREBPs}

Under basal conditions, the C-terminal domain of SREBPs binds to SREBP-cleavage activating protein (SCAP) in the ER membrane. This SREBP-SCAP complex interacts with insulininduced gene 1 protein (INSIG1) and INSIG2 (Yabe et al., 2002; Yang et al., 2002). In the presence of high cellular cholesterol and oxycholesterol levels, INSIGs become stable and bind to SREBP-SCAP creating a complex retained in the ER membrane. When the level of sterols is low, INSIGs are ubiquitylated by the associated E3 ligases and rapidly degraded (Gong et al., 2006). Meanwhile, the proteolytic activation of SREBP1 is induced by insulin and high glucose and inhibited by polyunsaturated fatty acids (PUFAs) (Nakakuki et al., 2014; Cheng et al., 2015). Insulininduced Akt activation is shown to decrease INSIG2a protein pools, resulting in increased ER-to-Golgi transport of the SCAPSREBP1c complex (Yellaturu et al., 2009). SCAP escorts SREBP insertion on ER transport vesicles containing COP II vesicle coat protein. The SREBP-SCAP complex is then transported to the Golgi apparatus (Sun et al., 2005). In the Golgi, the ER luminal loop of SREBP is initially cleaved by site-1 protease (S1P), a membrane-bound serine protease. Subsequent cleavage by site- 2 protease ( $\mathrm{S} 2 \mathrm{P})$, a $\mathrm{Zn}^{2+}$ metalloprotease, generates transcriptionally active N-terminal domains (Ye et al., 2000), which are translocated to the nucleus mediated via importin $\beta$ (Lee et al., 2003) (Figure 2).

Several kinases have also been reported to be involved in the regulation of proteolytic activation. PAS kinase (PASK), a serine/threonine kinase, is required for the proteolytic maturation of SREBP1c in cultured cells and mice and rat liver. However, the detailed signaling mechanism and its effect on the stability or transcriptional activity of nuclear SREBP1c have not been fully investigated (Wu et al., 2014), whereas AMPactivated protein kinase (AMPK) has been recently identified as an upstream regulator of INSIG1. AMPK phosphorylates INSIG1 (Thr222), abrogates its interaction with E3 ubiquitin ligase gp78, and represses its ubiquitination and degradation. Increased INSIG1 stabilization eventually inhibits the cleavage and processing of SREBP1 (Han et al., 2019).

\section{Regulation of SREBPs Synthesis and Nuclear Activity}

SREBP1c gene transcription is activated by the liver $\mathrm{X}$ receptor (LXR), which is modulated by insulin, PUFAs, and oxysterols. The LXR-retinoid $\mathrm{X}$ receptor heterodimer interacts with the LXR-responsive elements located in the SREBP1c promoter, initiating SREBP1c gene transcription (Yoshikawa et al., 2001). Activation of the farnesoid X receptor (FXR) induces small heterodimer partner (SHP) expression, leading to inhibition of LXR and reduced SREBP1c expression (Watanabe et al., 2004; Figure 3).

The transcription of SREBP target genes is tightly regulated by nuclear SREBP stability (Hirano et al., 2001). Mammalian target of rapamycin complex 1 (mTORC1), a major downstream element of insulin-induced phosphatidylinositol 3-kinase (PI3K)/Akt, activates SREBP1 depending on its S6-kinase 1 activity (Düvel et al., 2010). mTORC1 also promotes SREBP via the phosphorylation of lipin1, a phosphatidic acid phosphatase. Dephosphorylated lipin-1 triggers lipin-1 nuclear localization, reduces nuclear SREBP, and alters the localization of SREBP to the nuclear periphery (Peterson et al., 2011). In addition, nuclear SREBPs undergo posttranslational modifications. Glycogen synthase kinase 3 (GSK3) phosphorylates nuclear SREBP1a (Ser-434), which serves as a recognition motif for Fbw7 ubiquitin ligases, leading to SREBP1a degradation (Bengoechea-Alonso and Ericsson, 2009). AMPK directly phosphorylates both precursor and nuclear SREBP1c (Ser372), decreasing SREBP1c cleavage and nuclear translocation (Li Y. et al., 2011). $\mathrm{NAD}^{+}$dependent deacetylase Sirtuin 1 (SIRT1) deacetylates and inhibits SREBP1c transactivation by enhancing ubiquitination (Bengoechea-Alonso and Ericsson, 2009; Figure 3).

Furthermore, cyclin-dependent kinase 8 (CDK8) and its regulatory partner cyclin $\mathrm{C}(\mathrm{CycC})$ have been identified to cause the phosphorylation of nuclear SREBP1c at a conserved 


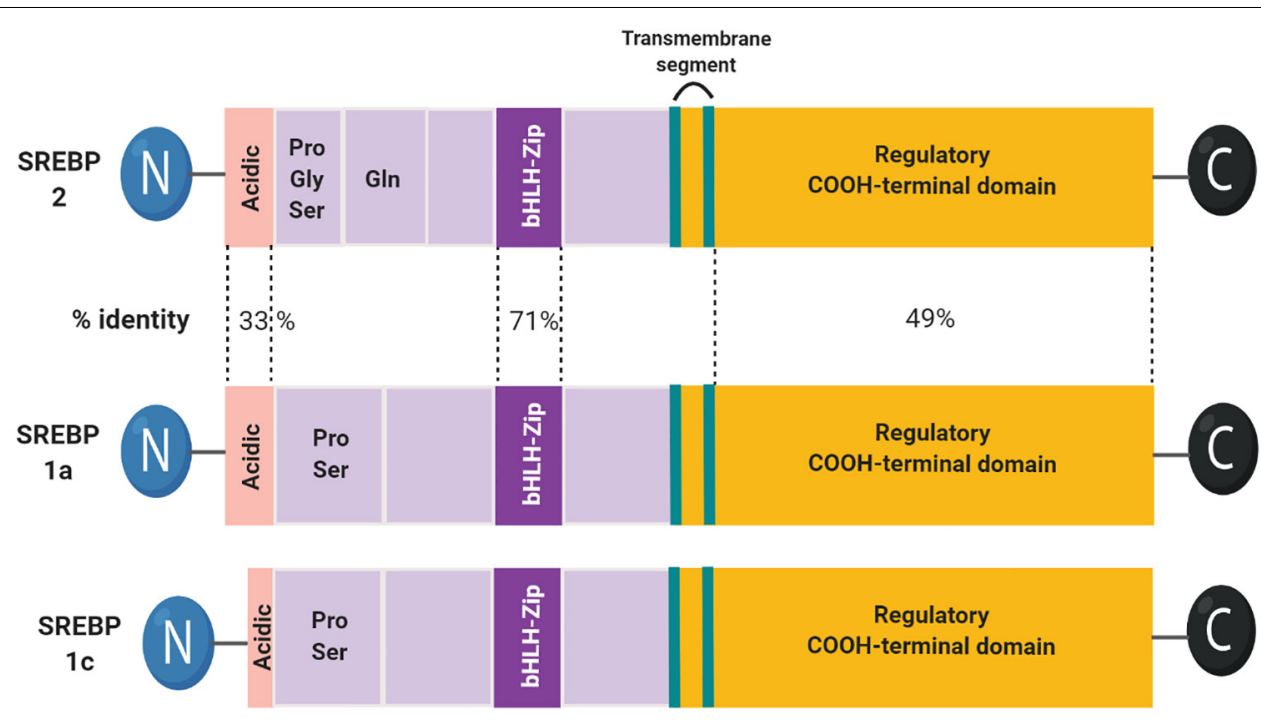

FIGURE 1 | Domain structure of the SREBP family. The structure of SREBP1c is highly similar to SREBP1a. SREBP1c has a shorter transactivation domain in the N-terminus.

threonine residue (T402), leading to increased nuclear SREBP1c ubiquitination and degradation. Interestingly, $\mathrm{CDK} 8$ and $\mathrm{CycC}$ are negatively regulated by feeding and insulin, the most widely studied stimuli that promote SREBP1 activation (Zhao et al., 2012). Protein kinase A (PKA) also regulates nuclear SREBP1c stability. Under fasting conditions, glucagon-induced PKA activation stimulates the phosphorylation of SREBP1c (Ser308) (Lee et al., 2014) and SREBP1a (Ser331/332) (Dong et al., 2014). This promotes the sumoylation of SREBP1c at Lys 98 by the mammalian protein inhibitor of activated STAT (PIAS)y, a SUMO E3 ligase. Sumoylated SREBP1c is readily degraded by ubiquitination, which leads to decreased hepatic lipid metabolism (Lee et al., 2014).

\section{Classical DNA Binding Sites of SREBPs}

Intra-nuclear SREBPs were initially found to bind to HMG CoA reductase (HMGCR) and LDL receptor (LDLR) gene promoters, known as sterol response elements (SREs). The original SRE sequence is $5^{\prime}$-ATCACCCCAC-3' (Hua et al., 1993). In addition to non-palindromic SREs, the SREBPs bind to and activate classic palindromic E-boxes (CAXXTG sequence) containing promoter (Kim et al., 1995). This dual binding specificity allows SREBPs to bind with various cholesterolgenic and lipogenic genes, whose SREs are relatively similar to the original SRE sequence found in the LDLR gene. The sequences of the SREBP binding and activation sites vary considerably and are designated SRE-like sequences (Shimano, 2001; Figure 4).

SREBP1 activates lipogenic genes, whereas SREBP2 is more specific for cholesterolgenic genes. SREBP1a and -2 are equally active for SRE, whereas SREBP1c is inactive. However, only SREBP1a and -1c are active for E-box (Amemiya-Kudo et al., 2000). Due to the high similarity between the N-terminal domains of the three isoforms, all SREBP isoforms can activate each of their target genes but with different efficacies. As
SREBP1c contains a shorter transactivation domain, it is weaker than SREBP1a and SREBP2. In contrast, the C-terminal domains of SREBP1 and SREP-2 are relatively less conserved compared to other domains, which may lead to minor differences in the sterol regulation mechanism (Shimano et al., 1997; Pai et al., 1998).

\section{SREBPs Mediate Renal Lipotoxicity}

Altered lipid metabolism has been linked to the progression of both acute and CKDs. Microarray analysis of human kidney biopsies in the Nephroseq database ${ }^{1}$ revealed a higher expression of SREBF1 and SREBF2 in patients with CKD or diabetic kidney disease (DKD) than in normal patients according to the results reported in $J u$ CKD Glom (Ju et al., 2013), Nakagawa CKD (Nakagawa et al., 2015), and Woroniecka Diabetes Glom (Woroniecka et al., 2011; Na et al., 2015). Furthermore, nutrient and genetic manipulations in experimental animal studies have demonstrated increased SREBP expression, which was associated with renal lipid accumulation, as well as progressive kidney injuries (Table 1).

The accumulation of non-esterified fatty acids and their metabolites in the kidney leads to cellular dysfunction and death through various mechanisms, such as altered mitochondrial energy coupling, excessive reactive oxygen species generation, and stimulation of ER stress (Murea et al., 2010). Defective fatty acid oxidation (FAO) in renal tubular epithelial cells particularly plays a crucial role in the progression of kidney fibrosis. Genome-wide transcriptome studies of fibrotic human kidneys revealed a lower expression of key enzymes and regulators of FAO (Kang et al., 2015). Kidney biopsies of patients with DKD demonstrated abnormal lipid metabolism, which was

\footnotetext{
${ }^{1}$ http://www.nephroseq.org/
} 

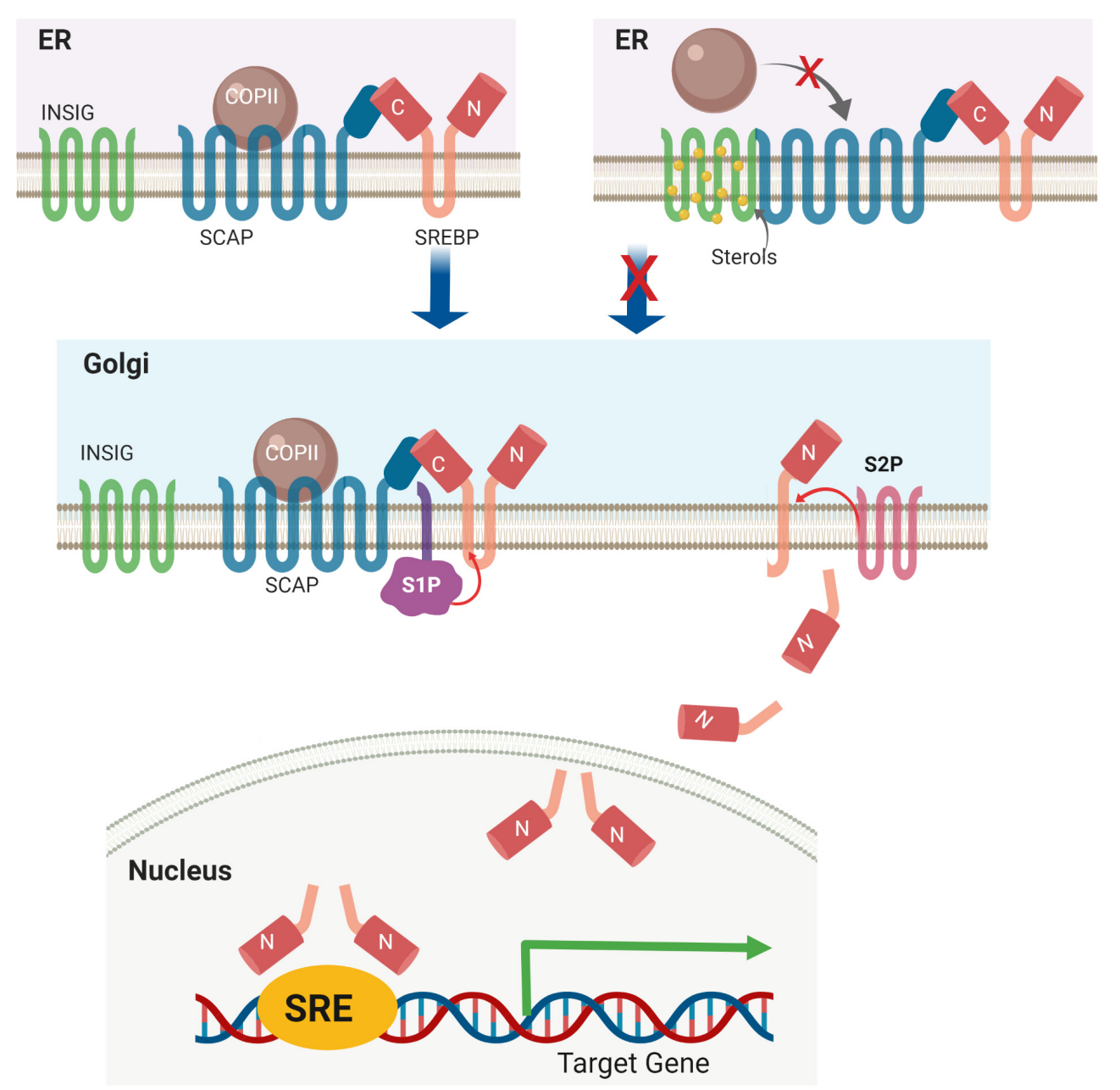

FIGURE 2 | Sterol-mediated proteolytic activation of SREBP. Under basal conditions, the SREBP-SCAP-INSIG complex is retained in the ER membrane. High levels of cellular sterol induce INSIG degradation, followed by translocation of the SREBP-SCAP complex from the ER to the Golgi apparatus. In the Golgi, SREBP is activated via a two-step proteolytic mechanism with S1P and S2P.

significantly correlated with a decline in glomerular filtration rate and kidney inflammation. The genes involved in the FAO pathway, TG hydrolysis, and cholesterol efflux were downregulated, whereas the cholesterol uptake receptor-related gene expression was elevated in the kidneys of human DKD patients (Herman-Edelstein et al., 2014).

\section{SREBP-Induced Lipotoxicity Also Applies to Other Organs}

In addition to kidney diseases, which are the focus of our review, the lipid accumulation induced by SREBP has been demonstrated to aggravate disease progression in other organs, such as the liver and lungs. Increased SREBP activity in the liver causes hepatic steatosis (Shimomura et al., 1999a), that can eventually progress to liver fibrosis and liver failure (Cohen et al., 2009). Specifically in the liver, the synthesis and proteolytic processing of SREBP1c is mainly triggered by insulin (Shimomura et al., 1999b; Brown and Goldstein, 2008). When insulin resistance is evident in peripheral tissues, insulin continues to activate SREBP1c transcription and proteolytic cleavage. Thus, the upregulated nuclear SREBP1c enhances lipogenic gene expression, fatty acid synthesis, and TG accumulation (Shimomura et al., 1999a, 2000). Meanwhile, lipid homeostasis in the lung is precisely regulated to maintain proper lung function, partially regulated by SREBP1c expression. The deletion of SCAP was shown to inhibit SREBP activity in alveolar type 2 cells and enhance neutral lipid accumulation in the lung fibroblasts of fetal and postnatal mice (Besnard et al., 2009). Double Insig1 and Insig2 gene deletions in alveolar type 2 cells activated SREBP1, leading to cholesterol esters and TG accumulation in type 2 epithelial cells and alveolar macrophages. Enhancing lipogenesis in respiratory epithelial cells resulted in lipotoxicity-related lung inflammation, airspace abnormalities, and tissue remodeling (Plantier et al., 2012). Aside from this lipid-dependent pathway, to our knowledge, there has been no study in the liver and lungs elucidating the mechanism of SREBP in mediating fibrotic signaling through a lipid-independent pathway. 


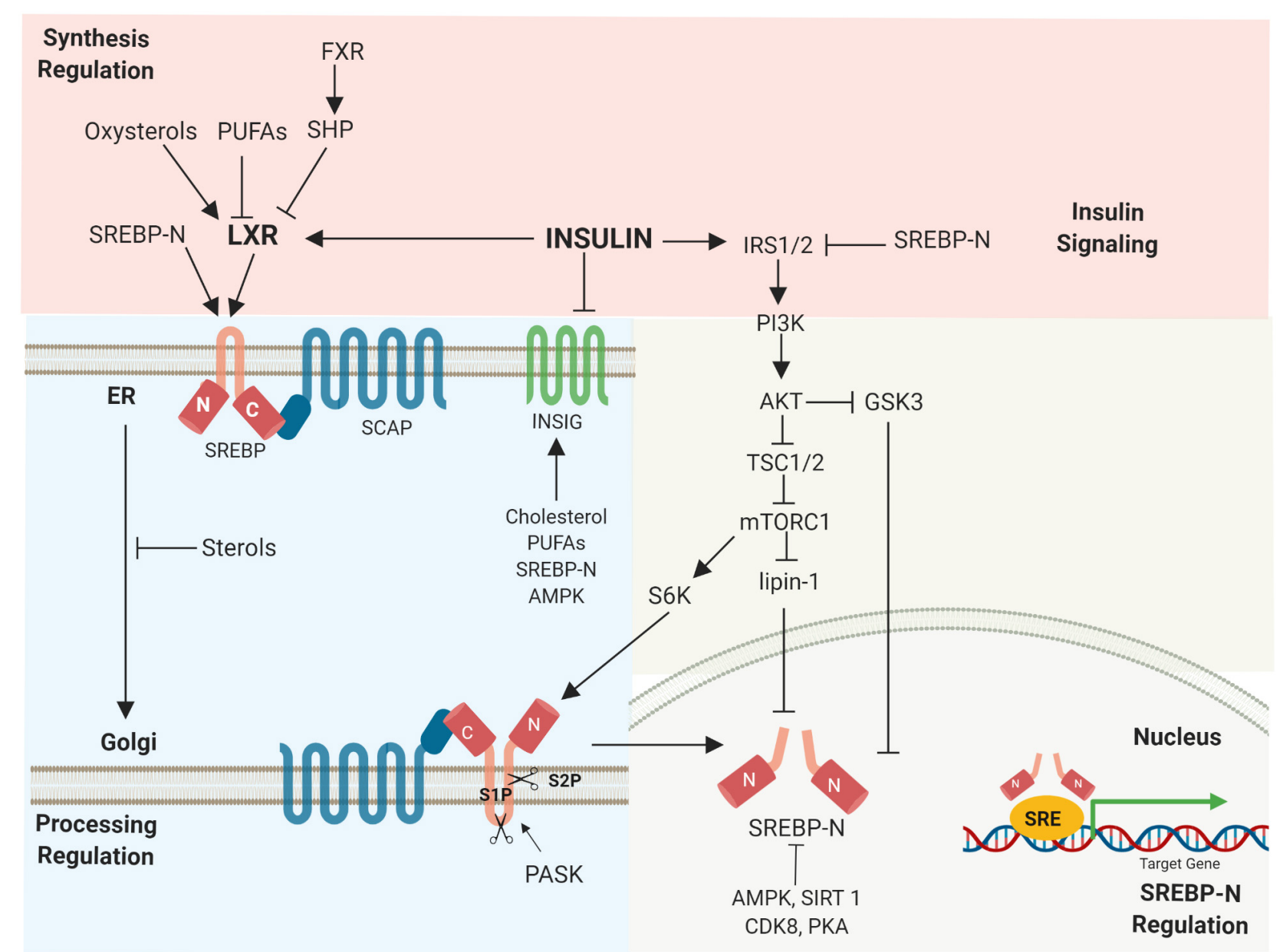

FIGURE 3 | Regulation of SREBPs occurs at various stages. Multiple signals regulate SREBP synthesis, proteolytic activation, transcriptional activity, as well as degradation. Activated, nuclear SREBP is tightly controlled by post-translational modifications.

\section{SREBP AS A PRO-FIBROTIC MEDIATOR IN THE KIDNEY}

Although most of the early works have already shown the role of SREBP in lipotoxicity-induced progressive tissue injuries and fibrosis development, a plausible role for SREBP in directly mediating the activation of fibrotic signaling has been underscored. SREBP was initially reported to induce extracellular matrix (ECM) gene transcription in fibroblasts. The promoter of collagen (col) VI ( $\alpha 1)$ contains a growth arrest-responsive region (GARR), comprised of repeat GA-box motifs (GGGGAGGG). In NIH3T3 fibroblasts cultured in serum-free medium, SREBP bound to GARR and induced Col VI $(\alpha 1)$ transcription (Ferrari et al., 2004). Plasminogen activator inhibitor 1 (PAI1), a serine protease with pro-fibrotic properties, has been also identified as a transcriptional target of SREBP1c in 3T3-L1 adipocytes (Lay et al., 2002). Following these precedent reports, a series of studies in the kidney were performed to further demonstrate a transcriptional effect of SREBP on the fibrotic signaling pathway.

\section{Non-sterol-mediated SREBP Activation}

As described in the previous section, the activation of SREBP is classically regulated by cellular sterol levels. Other tissueinjury stimuli, such as mechanical cues (Liu et al., 2002; Lin et al., 2003) and high glucose (HG) (Hasty et al., 2000; GuilletDeniau et al., 2004; Uttarwar et al., 2012), have been reported to induce SREBP activation, as well. However, the signaling mechanism of non-sterol-mediated SREBP activation appears to depend on the type of stimulus. SREBP1 activation in endothelial cells exposed to shear stress requires signaling via $\beta 1$ integrin, focal adhesion kinase, and c-Src (Liu et al., 2002). The shear stress activates SREBP2 in vascular endothelial cells via RhoA/Rho-kinase signaling. The Rho-ROCK-LIMK-cofilin pathway enhances the actin assembly needed for SREBP transport from the ER to Golgi (Lin et al., 2003). In recent work, ECM stiffening and geranylgeranylated RhoA-dependent acto-myosin contraction were also shown to activate AMPK, resulting in inhibition of SREBP1 activation (Bertolio et al., 2019).

Glucose has been shown to activate SREBP1 in renal tubular epithelial cell lines (Jun et al., 2009). Several studies 


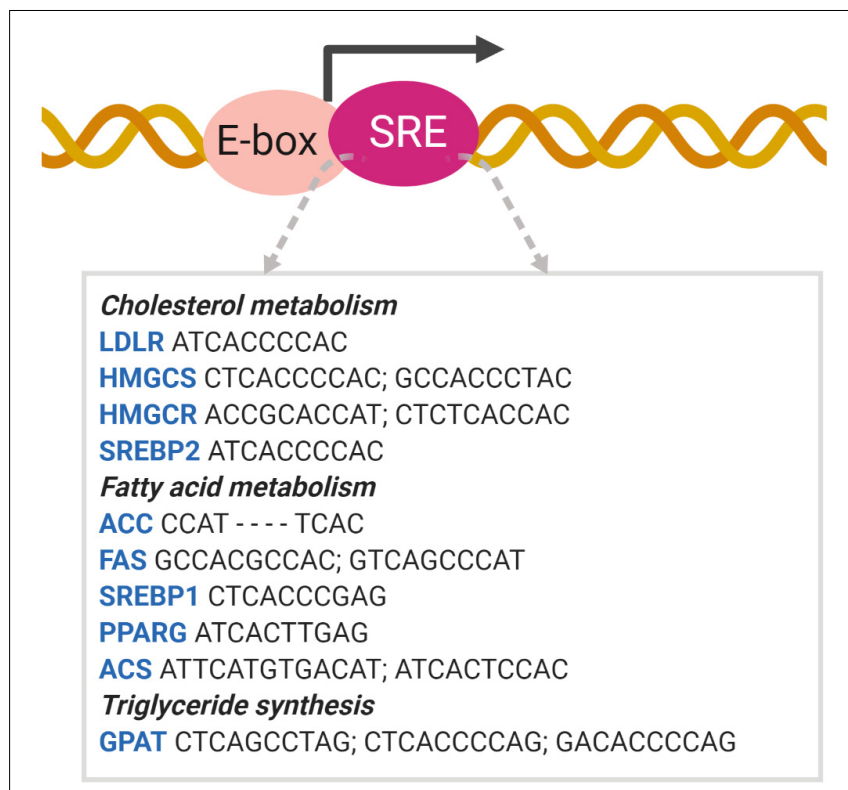

FIGURE 4 | SREBP binds to the SRE promoter. SREBP binding to the SRE promoter activates the transcription of target genes involved in lipid metabolism (Shimano, 2001). ACC acetyl-CoA carboxylase; ACS acetyl-CoA synthetase; GPAT glycerol-3-phosphate acyltransferase; HMGCS HMG-CoA synthase; PPAR peroxisome proliferator-activated receptor.

have suggested that epidermal growth factor receptor (EGFR)/PI3K/Akt (Wu et al., 2007, 2009) and RhoA/Rhokinase (Peng et al., 2008) signaling mediate HG-induced TGF $\beta$ upregulation and ECM accumulation in the kidney. A mechanistic study with primary rat mesangial cells (MCs) confirmed the role of these signaling in mediating HG-induced SREBP1 activation, which leads to TGF $\beta$ activation. S1P and SCAP were required for SREBP1 activation, as it was blocked by chemical inhibitors of S1P and SCAP (Wang T. N. et al., 2015). Despite the technical limitations associated with the differentiation of the two isoforms of SREBP1, these studies suggested that multiple factors activate SREBP1, which is associated with kidney injuries. By utilizing more recent and sensitive techniques, it remains challenging to differentiate the SREBP isoforms activated by specific stimuli and the respective downstream signaling in the kidney.

\section{SREBP Regulates TGF $\beta$ Activity}

Particularly in the kidney, SREBP has then been shown to be activated by several non-sterol stimuli and to contribute to the activation of fibrotic signaling, i.e., TGF $\beta$, a multifunctional cytokine that classically plays a major role in progressive kidney fibrosis (Sureshbabu et al., 2016).

\section{SREBP Induces TGF $\beta$ Transcriptional Activity}

HG increased TGF $\beta$ activity via SREBP1 activation in primary rat MCs. As early as $30 \mathrm{~min}$ and persisting up to $6 \mathrm{~h}, 30 \mathrm{mM}$ HG activated SREBPs based on the detection of its mature form (nSREBP1), whereas SREBP2 was not activated. HG promoted SREBP1 binding to the TGF $\beta$ promoter, which contains a putative SREBP1 binding site, SRE. This binding was halted by fatostatin and dominant-negative SREBP1a Y335A. Connective tissue growth factor (CTGF) was detected as the downstream target of TGF $\beta$ activation. Interestingly, TGF $\beta$ promoter analysis revealed that a potential SRE site was within the first 100 base pairs of the start codon. The site is located apparently in close proximity to the Sp1 site, a well-known coactivator of SREBP (Uttarwar et al., 2012).

Angiotensin (Ang)-II also stimulated SREBP1-induced TGF $\beta$ signaling in primary rat MC cultures. Treatment with 100 nM Ang II induced SREBP1 maturation, activated SREBP1 as detected by responsive SRE, and increased the SREBP downstream target, fatty acid synthase (FAS), leading to lipid accumulation. Then, Ang II activated two parallel signals essential for TGF $\beta$ promoter activation, ER stress-induced SREBP1 activation and EGFR-mediated activation of cotranscription factor Sp1. ER stress and SREBP1 activation were detected in the glomeruli of Ang II infused mice. SREBP1 inhibition by fatostatin prevented Ang II-induced TGF $\beta$ upregulation and ECM accumulation. Mechanistically, Ang IIinduced SREBP1 activation in MC culture required angiotensin (AT)1 receptor/PI3K/Akt signaling (Wang T. N. et al., 2015). PI3K and Akt are the downstream signaling molecules of AT1 receptor via coupling to G-proteins that positively regulate SREBP activation (Yellaturu et al., 2009; Uttarwar et al., 2012). Ang II-induced ER stress, exhibited by increased p-eIF2 $\alpha$ and GRP78 expression, also activated SREBP1 in MC culture. Inhibition of ER stress or SREBP1 prevented Ang II-induced SREBP1 binding to the TGF $\beta$ promoter (Wang T. N. et al., 2015). Another study showed that ER stress decreased INSIG via eIF2 $\alpha$ translational inhibition, resulting in the proteolytic activation of SCAP/SREBP. GRP78 retained SCAP/SREBP1 in the ER via direct interaction, which was disrupted during ER stress (Colgan et al., 2011). However, this Ang II/ER stress/SREBP activation needs to be confirmed in experimental animal models to provide stronger evidence. As Ang II might also induce ER stress in podocytes (Ha et al., 2015) and proximal tubular epithelial cells (Wang J. et al., 2015), other studies with these kidney cell subtypes are needed, as well. EGFR may be an important second signal in TGF $\beta$ upregulation via activation of the SREBP1 cotranscription factor Sp1. However, EGFR was not required for either SREBP1 activation or TGF $\beta$ promoter binding by SREBP1 (Wang T. N. et al., 2015).

A recent study suggested the role of lysophosphatidic acid (LPA) in SREBP-induced TGF $\beta$ activity (Li et al., 2017). LPA is a small, ubiquitous phospholipid that mediates pro-inflammatory and pro-fibrotic signaling in the kidney (Zhang et al., 2017). TGF $\beta$ and Smad-2/3 phosphorylation were upregulated in the renal cortex of $\mathrm{db} / \mathrm{db}$ mice and SV40 MES13 MCs stimulated with LPA. LPA bound to its receptor and activated PI3K/Akt phosphorylation, leading to phosphorylation of GSK3 $\beta$ at Ser9. The inactive, phosphorylated GSK3 $\beta$ decreased SREBP1 degradation, induced its nuclear translocation, and eventually triggered TGF $\beta$ transcriptional activity. Inhibition of either LPA receptor or SCAP by fatostatin significantly decreased TGF $\beta$ signaling and ECM accumulation in mesangial cells (Li et al., 2017). 
TABLE 1 | SREBPs and their target gene expressions mediating renal lipid accumulation and disease progression.

\begin{tabular}{|c|c|c|c|c|c|c|}
\hline $\begin{array}{l}\text { Experimental } \\
\text { condition }\end{array}$ & $\begin{array}{l}\text { SREBP in } \\
\text { kidney }\end{array}$ & $\begin{array}{l}\text { Expression of } \\
\text { target genes }\end{array}$ & $\begin{array}{l}\text { Lipid content } \\
\text { in kidney }\end{array}$ & Renal pathology & $\begin{array}{l}\text { Metabolic } \\
\text { changes }\end{array}$ & References \\
\hline \multicolumn{7}{|c|}{ TYPE 1 DIABETES MELLITUS } \\
\hline Ins2 Akita mice & $P: \uparrow 1,2$ & & $\begin{array}{l}\text { TC* } \uparrow 1.6 \text {-fold, } \\
\text { TG } \uparrow 1.4 \text {-fold }\end{array}$ & $\begin{array}{l}\uparrow \text { Urinary } \\
\text { albumin/creatinine } \\
\text { P: } \uparrow \text { COL4A1, FN1* } \\
\text { R: } \uparrow \text { Tgfb, Pai1, Vegf*, Tnfa } \\
\text { R: } \downarrow \text { Synpo*, Nphs2* }\end{array}$ & & Proctor et al., 2006 \\
\hline OVE26 mice & $\mathrm{R}: \uparrow 1 \mathrm{c}, 2$ & $\begin{array}{l}\mathrm{R}: \uparrow A c c, \text { Fas, } \\
\mathrm{Hmgcr} \\
\mathrm{R}: \uparrow \text { Pparg }\end{array}$ & & $\begin{array}{l}\mathrm{R}: \uparrow \text { Fn1*, Col4a1, II6, Tnfa } \\
\mathrm{R}: \downarrow \text { Synpo*, Nphs2* }\end{array}$ & & Proctor et al., 2006 \\
\hline \multicolumn{7}{|c|}{ TYPE 2 DIABETES MELLITUS } \\
\hline $\mathrm{FVB}^{d b / d b}$ mice & $P: \uparrow n 1,2$ & $\begin{array}{l}\mathrm{R}: \uparrow \text { Fas, Acc, } \\
\text { Hmgcr, Ldllr }\end{array}$ & $\begin{array}{l}\text { TC* } \uparrow 2.2 \text {-fold } \\
\text { TG } \uparrow 2.4 \text {-fold }\end{array}$ & $\begin{array}{l}\uparrow \text { Urinary } \\
\text { albumin/creatinine } \\
\uparrow \mathrm{GBM}^{*} \text { thickness, } \\
\text { podocyte foot process } \\
\text { length } \\
\mathrm{R}: \uparrow \text { Tgfb, Pai1, Vegf* }\end{array}$ & $\begin{array}{l}\text { BW* } \\
\text { TC* } \uparrow 2.1 \text {-fold } \\
\text { TG } \uparrow 1.6 \text {-fold }\end{array}$ & Wang et al., 2005 \\
\hline $\begin{array}{l}\text { C57BL/6J mice } \\
\text { with HFD* }\end{array}$ & $\begin{array}{l}\mathrm{P}: \uparrow n 1,2 \\
\mathrm{R}: \uparrow 1 \mathrm{a}, 1 \mathrm{c}, 2\end{array}$ & $\begin{array}{l}\mathrm{R}: \uparrow \text { Fas, Acc, } \\
\mathrm{Hmgcr}\end{array}$ & $\begin{array}{l}\text { TC* } \uparrow 1.2 \text {-fold } \\
\text { TG } \uparrow 3 \text {-fold }\end{array}$ & $\begin{array}{l}\uparrow \text { Urinary } \\
\text { albumin/creatinine } \\
\text { P: } \uparrow \text { COL4A1, FN1*, PAl1, } \\
\text { VEGF* }\end{array}$ & $\begin{array}{l}\text { BW* } \\
\text { TC* } \uparrow 1.4 \text {-fold } \\
\text { TG } \uparrow 1.2 \text {-fold } \\
\text { Insulin } \\
\uparrow 13.4 \text {-fold }\end{array}$ & Jiang et al., 2005c \\
\hline $\begin{array}{l}\text { STZ*-induced } \mathrm{SD}^{*} \\
\text { rats fed with HFD*\& } \\
\text { sucrose diet }\end{array}$ & $\begin{array}{l}P: \uparrow 2, n 2 \\
R: \uparrow 2\end{array}$ & $\begin{array}{l}\mathrm{P}: \uparrow \mathrm{HMGCR} \\
\text { LDLR }\end{array}$ & & $\begin{array}{l}\uparrow \text { Serum Creatinine, BUN*, } \\
\text { Albuminuria, Urinary NGAL* }\end{array}$ & 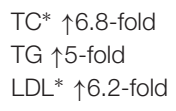 & Sun et al., 2013 \\
\hline \multicolumn{7}{|l|}{ HYPERTENSION } \\
\hline $\begin{array}{l}\text { Angll infused SD* } \\
\text { rats }\end{array}$ & $\mathrm{P}: \uparrow 1$ & & $\begin{array}{l}\text { TC* } \uparrow 1.5 \text {-fold } \\
\text { TG } \uparrow 1.5 \text {-fold }\end{array}$ & $\mathrm{P}: \uparrow$ TGFB & $\begin{array}{l}\mathrm{BP}^{*} \\
\mathrm{TC}^{*} \uparrow 1.3 \text {-fold } \\
\mathrm{TG} \uparrow 2 \text {-fold }\end{array}$ & Saito et al., 2005 \\
\hline $\begin{array}{l}\text { F344BN rats, } 24 \\
\text { months vs. } 4 \\
\text { months }\end{array}$ & $P: \uparrow n 1, n 2$ & $\mathrm{P}: \uparrow \mathrm{HMGCR}$ & $\begin{array}{l}\text { TC* } \uparrow 1.5 \text {-fold } \\
\text { TG } \uparrow 2.6 \text {-fold }\end{array}$ & $\begin{array}{l}\uparrow \text { Urinary } \\
\text { albumin/creatinine } \\
\mathrm{P}: \uparrow \text { COL4A1, FN1* } \\
\text { CTGF, PAl1, VEGF* }\end{array}$ & $\begin{array}{l}\text { TC* } \uparrow 1.5 \text {-fold } \\
\text { TG } \uparrow 2 \text {-fold } \\
\text { Leptin } \\
\uparrow 5.6 \text {-fold }\end{array}$ & Jiang et al., 2005b \\
\hline $\begin{array}{l}\text { SD* rats, } 24 \\
\text { months vs. } 6 \\
\text { months }\end{array}$ & $P: \uparrow 1$ & & $T G \uparrow 2$-fold & $\begin{array}{l}\uparrow \text { Serum Urea, Serum } \\
\text { KIM1* } \\
\text { P: } \uparrow \text { COL1A1, COL4A1, } \\
\text { FN1* }\end{array}$ & & Chung et al., 2018 \\
\hline \multicolumn{7}{|c|}{ GENETICALLY MODIFIED MICE } \\
\hline $\begin{array}{l}\text { Transgenic } \\
\text { SREBP1a }\end{array}$ & $\mathrm{P}: \uparrow 1$ & $\mathrm{R}: \uparrow F a s, A c c$ & $\begin{array}{l}\text { TC* } \uparrow 1.2 \text {-fold } \\
\text { TG } \uparrow 2.5 \text {-fold }\end{array}$ & $\begin{array}{l}\uparrow \text { Urinary } \\
\text { albumin/Creatinine } \\
\mathrm{P}: \uparrow \text { COL4A1, FN1* } \\
\text { TGFB, VEGF* }\end{array}$ & $\begin{array}{l}\text { Liver TG } \\
\uparrow 20 \text {-fold } \\
\text { TC* } \uparrow 3.5 \text {-fold }\end{array}$ & Sun et al., 2002 \\
\hline SREBP1c knockout & & & $\begin{array}{l}\text { TG } \downarrow 1.7 \text {-fold } \\
\text { (vs WT* in } \\
\text { HFD* group) }\end{array}$ & $\begin{array}{l}\mathrm{R}: \downarrow \text { Col4a1, Fn1*, Pai1, } \\
\text { Vegf*(vs WT* in HFD* } \\
\text { group) }\end{array}$ & $\begin{array}{l}\text { TG } \downarrow \uparrow 1.7 \text {-fold } \\
\mathrm{TC}^{*} \downarrow 1.2 \text {-fold } \\
\text { (vs WT* in ND* } \\
\text { group) }\end{array}$ & Jiang et al., 2005c \\
\hline
\end{tabular}

*BP, blood pressure; BUN, blood urea nitrogen; BW, body weight; FN1, fibronectin; GBM, glomerular basement membrane; HFD, high-fat diet; KIM1, kidney injury molecule; LDL, Iow-density lipoprotein; n,nucleus; ND, normal diet; NGAL, neutrophil gelatinase-associated lipocalin; NPHS2, stomatin family member, podocin; P, protein; R, mRNA; SD rats, Sprague Dawley rats; STZ, streptozotocin; SYNPO, synaptopodin; TC, total cholesterol; VEGF, vascular endothelial growth factor; WT, wild-type. 
One should be aware that the cited evidence linking SREBP and TGF $\beta$ activation was derived from different experimental conditions or biological contexts. Those studies utilized EMSA and ChiP to discover the binding site motif, but the methods were limited by the skewed distribution of the genomic sequence and the inability to distinguish direct and indirect binding of the transcription factor (Lambert et al., 2018). A combination of methods with different throughput and information content, e.g., ChiP combined with SELEX, protein binding microarray/PBM, and MITOMI, are ideally necessary to determine and validate the precise genomic binding site of the transcription factor and how the transcription factor binding ultimately relates to the regulation of transcription (Geertz and Maerkl, 2010; Lambert et al., 2018).

\section{A Vicious Cycle of SREBP1 and TGF $\beta$ Activation}

Active SREBP1a, but not SREBP1c, activates the TGF $\beta$-responsive reporter plasmid p3TP-lux carrying the promoter region of PAI1 (Chen et al., 2014). Due to its additional $\mathrm{N}$-terminal residues, SREBP1a can bind to co-transcriptional factors, such as CREB-binding protein (CBP), making it a more potent transcriptional factor than SREBP1c (Toth et al., 2004). However, TGF $\beta$ activates not only its canonical pro-fibrotic downstream target, Smad3, but also non-canonical SREBP1, which requires SCAP, S1P, and P13K/Akt signaling (Figure 5). TGF $\beta$-induced PI3K/Akt signaling acts as a critical regulator of Smad3-CBP interaction and Smad3 acetylation, which results in the upregulation of PAI1 expression (Das et al., 2008). Moreover, TGF $\beta$-induced PI3K/Akt signaling stimulated acetylation of SREBP1a in the lysine residue (K333) by the acetyltransferase CBP, which enhanced the nuclear stability of SREBP1a. The active SREBPla was further bound to E-box, which was adjacent to the Smad-binding element (SBE). TGF $\beta$, interestingly, induced a direct association between Smad3 and acetylated SREBP1a in this adjacent area and the interaction between these two transcription factors was crucial in regulating the transcriptional activity of TGF $\beta$ (Chen et al., 2014). Along with previous observations suggesting that SREBP1 mediates the upregulation of TGF $\beta$ transcriptional activity (Uttarwar et al., 2012; Wang T. N. et al., 2015; Li et al., 2017), a positive feedback loop may exist in which SREBP1 exacerbates both TGF $\beta$ transcriptional activity and the response, to trigger progressive fibrosis (Figure 5).

\section{SREBP Prevents Exosomal Degradation of TGF $\beta$ Receptor (T $\beta R$ )}

As discussed above, SREBP1 coordinates TGF $\beta$ signaling via its interaction with Smad3 (Chen et al., 2014). The activation of Smad2/3 can be controlled at various levels, for example, via the turnover of T $\beta$ RI and T $\beta$ RII (Huang and Chen, 2012). SREBP1 inhibition by either fatostatin or SREBP1 siRNA decreased T $\beta R I$ expression and halted TGF $\beta /$ Smad 3 signaling. However, SREBP1 did not regulate T $\beta$ RI via transcription, proteasomal/lysosomal degradation, or proteolytic cleavage (Van Krieken et al., 2017).

Lipid rafts and caveolar endocytosis have been associated with the downregulation of T $\beta$ RI (Huang and Chen, 2012; Lan and Chung, 2012). Cyclodextrin-induced lipid raft disruption prevented T $\beta R I$ decreases, suggesting that SREBP1 regulated the cell surface expression of T $\beta$ RI in a lipid-raft dependent manner. However, T $\beta$ RI expression in MCs was found to be independent of caveolae since SREBP1 inhibition still induced T $\beta$ RI downregulation in caveolin-1 knockout MCs. SREBP1 may act as an important cell surface retention factor for T $\beta$ RI by preventing its secretion in the exosome (Figure 5). SREBP1 inhibition induced T $\beta$ RI secretion into exosomes, which has been implicated in intracellular organelle transfer (Van Krieken et al., 2017). However, this study did not exclude the plausible re-fusion of exosomes containing T $\beta R I$ in the adjacent MCs.

\section{POTENTIAL TARGETS OF SREBPS: BEYOND LIPID METABOLISM}

In a study by Seo et al. (2009), the genome-wide analysis of SREBP1 binding in mouse liver chromatin revealed a preference for proximal binding of the promoter to a new motif ( $5^{\prime}$ ACTACANNTCCC- $3^{\prime}$ ). Since then, many putative target genes of SREBPs have been shown to act beyond lipid metabolism, such as in autophagy (Seo et al., 2009), ER stress (Sanchez-Alvarez et al., 2014), as well as metabolic circadian rhythm (Gilardi et al., 2014).

\section{Identification of Non-lipogenic Target Genes of SREBPs}

Having been identified to promote the transcriptional activity of TGF $\beta$, we wondered whether other pro-fibrotic mediators could also be targets of SREBP regulation. Here, the potential SREBF target genes were identified using a data-mining suite powered by full integration of public chromatin immunoprecipitation (ChIP)-sequencing data, namely ChIP-Atlas ${ }^{2}$. The transcription regulatory peaks were examined from around $\pm 5 \mathrm{~kb}$ of the transcription start sequence of the coding genes (Figure 6). However, it should be noted that the genes listed as target genes are not necessarily functional targets of a given transcriptional regulator, suggesting that the actual regulation of potential target genes should be experimentally verified (Oki et al., 2018).

\section{Potential Targets of SREBPs for the Regulation of Fibrosis Development}

As summarized in Table 2, SREBFs are predicted to regulate various non-lipogenic genes in diverse tissues and cell lines. Among those genes, we discuss several SREBP target genes that are plausibly involved in the pathogenesis of tissue fibrosis. These target genes would be interesting to be directly investigated in an experimental disease model of either kidney or other organs.

\section{Claudin 34D (CLDN34D)}

Claudins are a family of tight-junction membrane proteins that have not been clearly elucidated in the kidney. Genetic mutations in claudin-16 and -19 cause familial hypomagnesemia and hypercalciuria with nephrocalcinosis,

\footnotetext{
${ }^{2}$ https://chip-atlas.org/
} 


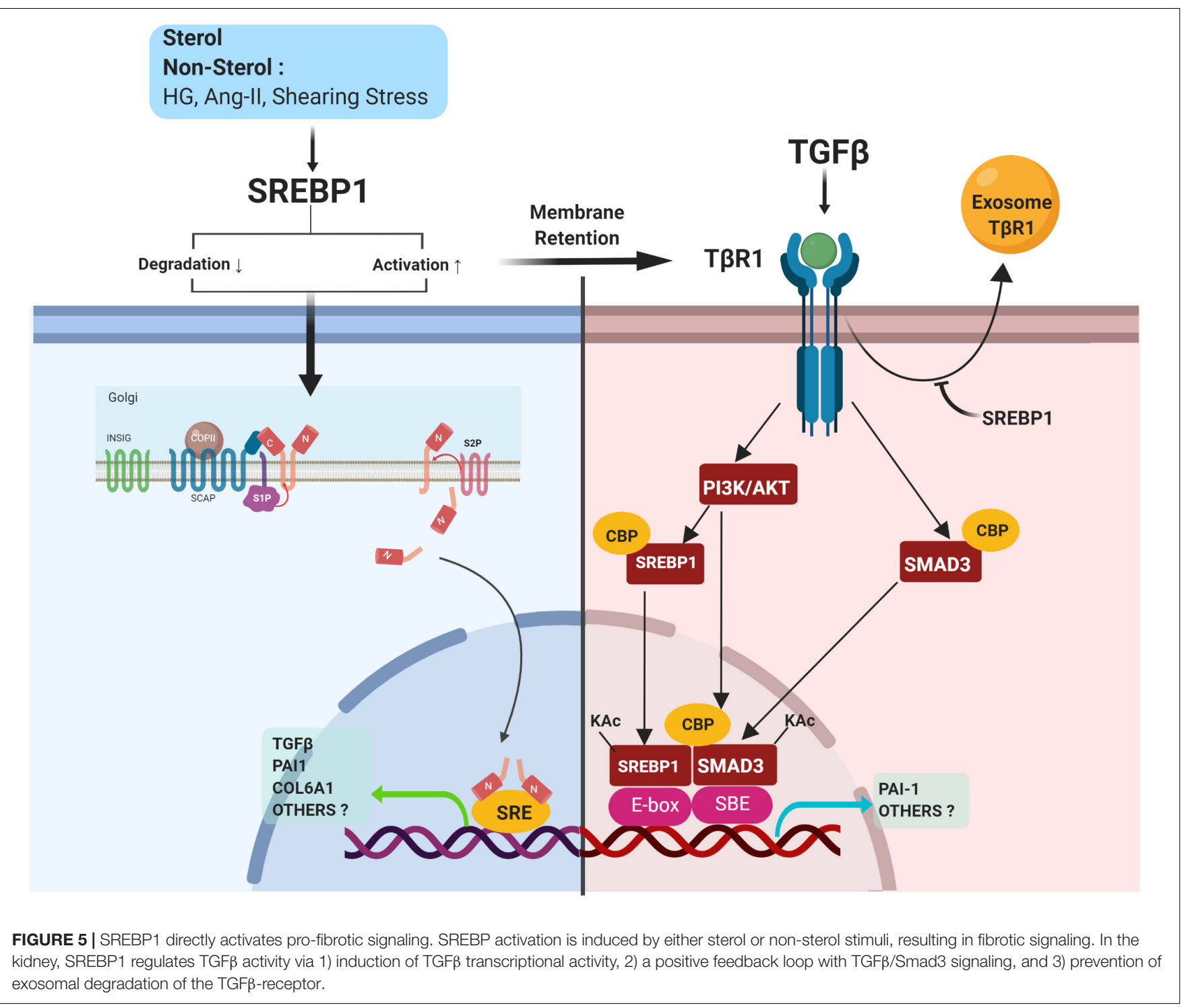

whereas polymorphisms in claudin-14 are associated with the risk of kidney stones ( $\mathrm{Li}$ J. et al., 2011; Yu, 2015). In the lung, the disruption of claudin-18 expression stimulates pulmonary fibrosis or chronic obstructive pulmonary disease (Schlingmann et al., 2015). Furthermore, claudin modification has been established in several cancers, including gastric cancer, via the activation of epithelial-to-mesenchymal transition (EMT), a mechanism that is also involved in the progression of fibrosis (Rendon-Huerta et al., 2013).

\section{Syndecan Binding Protein (Syntenin) 2 (SDCBP2)}

Syntenin was initially identified as a protein linking syndecanmediated signaling to the cytoskeleton (Grootjans et al., 1997). Syntenin positively regulates TGF $\beta$-mediated Smad activation and EMT by preventing the caveolin-1-mediated internalization of T $\beta$ RI (Hwangbo et al., 2016). Thus, this adapter protein might contribute to tissue fibrosis.

\section{Elastin Microfibril Interfacer 2 (EMILIN2)}

EMILIN is an elastic fiber-associated glycoprotein (Doliana et al., 2001). In the kidney, it is localized to the glomeruli and occurs predominantly in mesangial cells (Sterzel et al., 2000). EMILIN2 binds to the TNF-related apoptosisinducing ligand (TRAIL) death receptor (DR) 4 and partially with DR5 to activate the extrinsic apoptotic pathway. EMILIN2 knockdown results in enhanced cell survival and its overexpression triggers massive apoptosis (Mongiat et al., 2007). These additional mechanisms of ECM in modulating cell survival require further exploration in kidney diseases.

\section{Death Associated Protein Kinase 3 (DAPK3)}

DAPK is a calcium/calmodulin-regulated serine/threonine kinase that mediates cell death. Deletion of the kinase domain in DAPK attenuates tubular cell apoptosis in renal ischemiareperfusion injury (Kishino et al., 2004). DAPK3 induces 


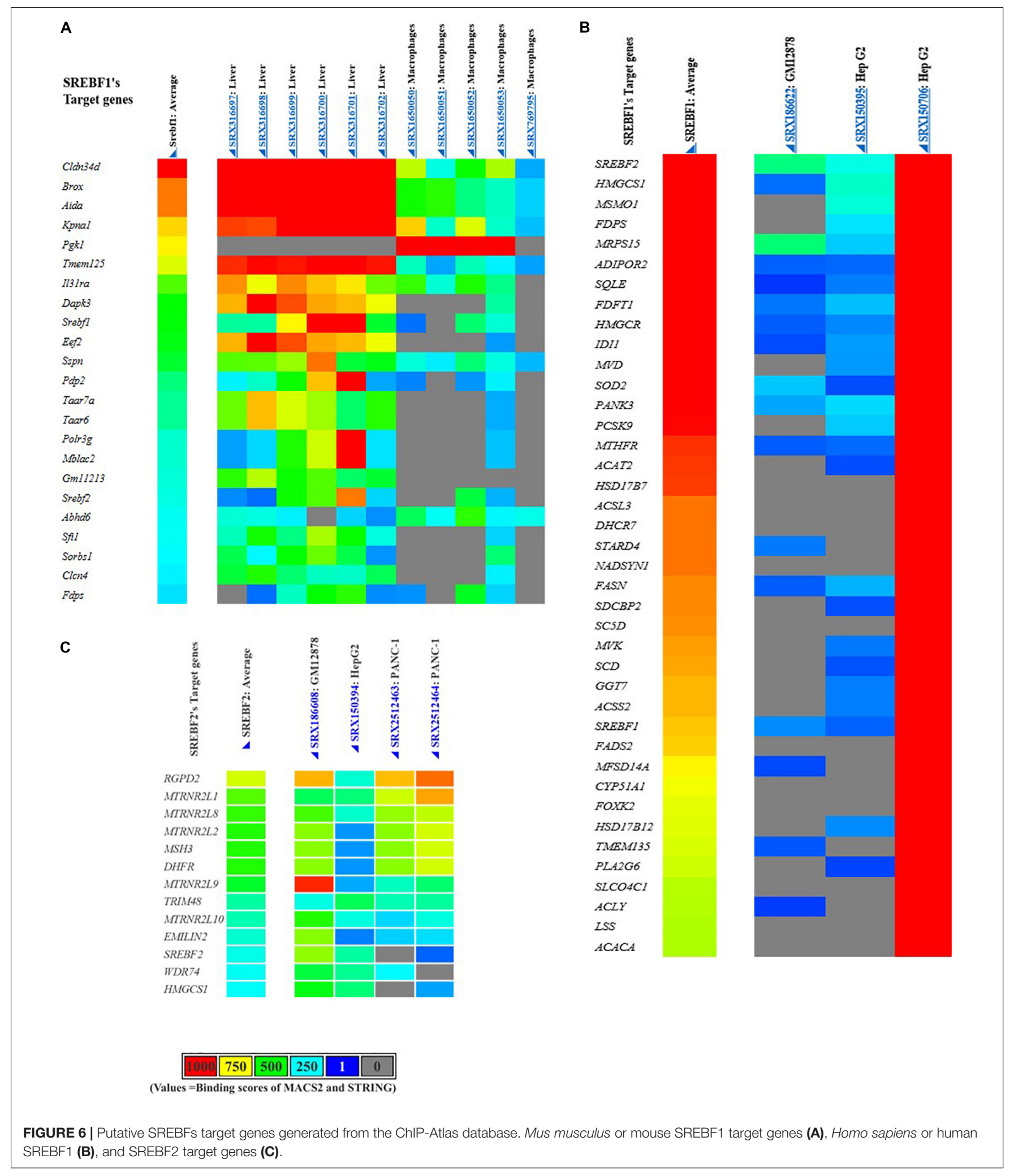

apoptosis or autophagy with or without caspase proteins. It (Elbadawy et al., 2018). However, it is unclear whether also mediates inflammatory signals L13a (ribosome protein), DAPK3 is a potential target for kidney protection against ERK, and interferon- $\gamma$-activated inhibition of translation cell death. 
TABLE 2 | Lipid and non-lipid targets of SREBF genes generated from the Chip-Atlas database (https://chip-atlas.org/).

\begin{tabular}{|c|c|}
\hline Biological Function & Target Genes \\
\hline \multicolumn{2}{|l|}{ SREBF1 MUS MUSCULUS } \\
\hline Lipid biosynthesis & Srebf1; Srebf2 \\
\hline \multicolumn{2}{|l|}{ Non-lipid targets } \\
\hline Antiport system & Clcn4 \\
\hline Associated protein of endosomal sorting complex & Brox \\
\hline Cytoskeleton and ECM & Sspn \\
\hline RNA polymerase activity & Polr3g \\
\hline Essential factor for protein synthesis & Eef2 \\
\hline Cell matrix adhesion & Sorbs1; Cldn34d \\
\hline Glycolytic enzyme & Pgk1 \\
\hline Hydrolase activity & Mblac2 \\
\hline Induction of apoptosis & Dapk3 \\
\hline Interleukin-31 receptor signaling & ॥/31ra \\
\hline Lipase activity & Abhd6 \\
\hline Nuclear protein import & Kpna1 \\
\hline Phosphatase activity & Pdp2 \\
\hline Structural protein of centrosome & Sfi1 \\
\hline Trace-amine receptor & Taar6; Taar7a \\
\hline Transmembrane protein & Tmem125 \\
\hline Ventralizing factor in embryogenesis & Aida \\
\hline \multicolumn{2}{|l|}{ SREBF1 HOMO SAPIENS } \\
\hline Lipid biosynthesis & $\begin{array}{l}\text { ACACA, ACAT2, ACLY, } \\
\text { ACSL3, ACSS2, } \\
\text { CYP51A1, DHCR7, } \\
\text { FADS2, FAS, FDFT1, } \\
\text { FDPS, HMGCR, } \\
\text { HMGCS1, HSD17B12, } \\
\text { HSD17B7, IDI1, LSS, } \\
\text { MSMO1, MVD, MVK, } \\
\text { SC5D, SCD, SQLE, } \\
\text { SREBF1, SREBF2, } \\
\text { STARD4 }\end{array}$ \\
\hline \multicolumn{2}{|l|}{ Non-lipid targets } \\
\hline Adiponectin signaling & ADIPOR2 \\
\hline Biosynthesis of coenzyme A & PANK3 \\
\hline Cell matrix adhesion & SDCBP2 \\
\hline Glutathione metabolism & SOD2 \\
\hline Mitochondrial translation & MRPS15 \\
\hline Peroxisome organization, mitochondrial fission & TMEM135 \\
\hline Phospholipase activity & PLA2G6 \\
\hline Transcriptional regulator & FOXK2 \\
\hline Transmembrane transporter & SLCO4C1 \\
\hline \multicolumn{2}{|l|}{ SREBF2 HOMO SAPIENS } \\
\hline Lipid biosynthesis & SREBF2; HMGCS1 \\
\hline \multicolumn{2}{|l|}{ Non-lipid targets } \\
\hline Anti-apoptotic & MT-RNR2L \\
\hline De novo synthesis of purines, thymidylic acid & DHFR \\
\hline DNA mismatch repair & MSH3 \\
\hline ECM constituent & EMILIN2 \\
\hline Ribosome biogenesis & WDR74 \\
\hline
\end{tabular}

\section{Transmembrane Protein 135 (TMEM135)}

TMEM135 is an LXR-inducible regulator of peroxisome catabolic and anabolic processes mediated via the auxiliary matrix protein

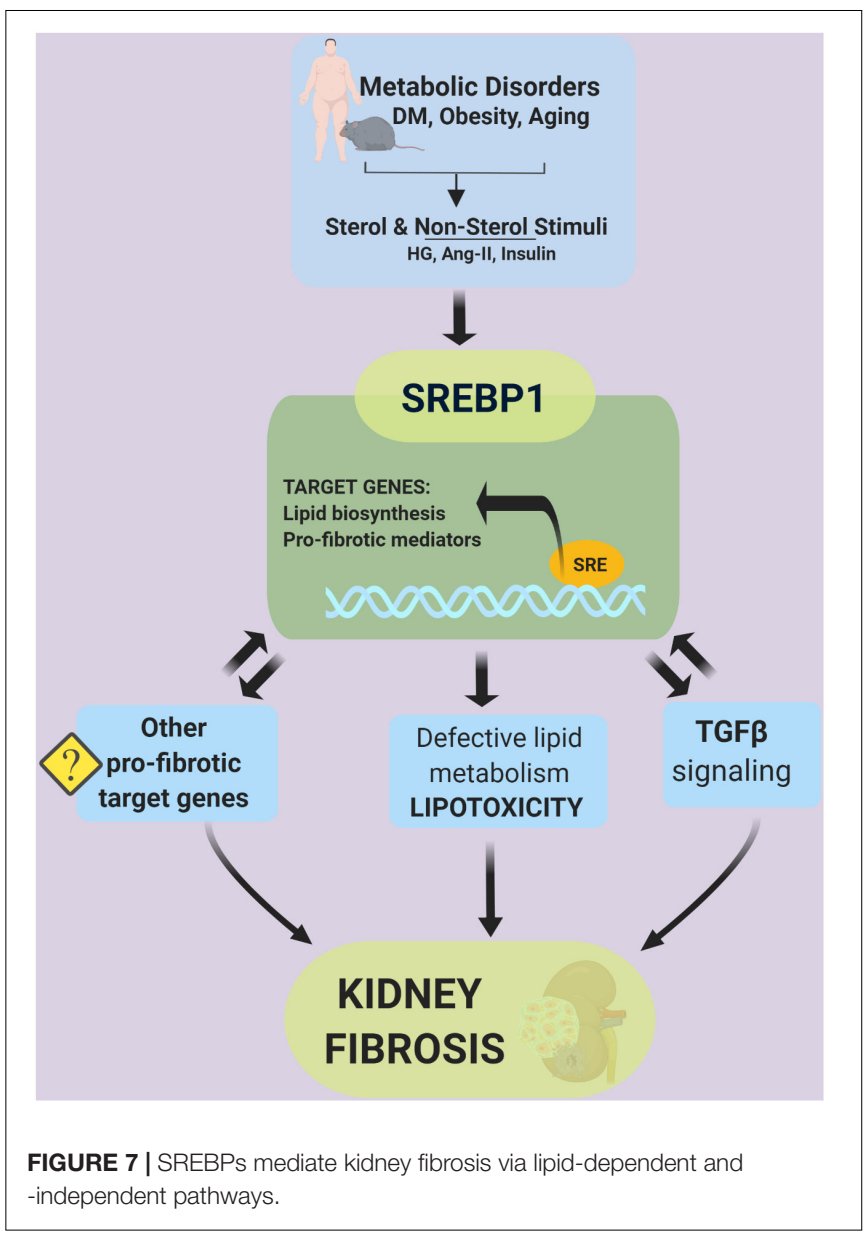

import pathway. It also regulates mitochondrial dynamics to protect the retina against oxidative stress and progressive retinal aging (Lee et al., 2016). Overexpression of TMEM135 increases mitochondrial fragmentation, as well as collagen accumulation and hypertrophy in the heart (Lewis et al., 2018). However, the role of TMEM135 in modulating mitochondria or peroxisomal function in kidney tissue remains elusive.

\section{FUTURE DIRECTIONS AND CONCLUSION}

Given the importance of SREBP in mediating lipid biosynthesis, which converges with various pathological signaling mechanisms, targeting SREBP is an important pharmacological strategy to attenuate the progression of kidney diseases. The available small-molecule inhibitors of SREBP activation have been comprehensively reviewed elsewhere (Watanabe and Uesugi, 2013). However, fatostatin is the only SREBP inhibitor extensively studied in kidney diseases. It inhibits the ER-Golgi translocation of SREBPs by binding to SCAP at a site distinct from the sterol-binding domain. Decreased SREBP maturation attenuates the progression of tubulointerstitial fibrosis induced by unilateral obstructive injury (Mustafa et al., 2016) and 
kidney injury in hypertensive mice (Wang T. N. et al., 2015). In type 1 diabetic mice, 12 -week fatostatin treatment blocked renal SREBP1 and SREBP2 expression. However, hyperfiltration, albuminuria, and kidney fibrosis were not attenuated in the diabetic mice. Non-diabetic mice treated with fatostatin exhibited hyperfiltration and increases in glomerular volume to levels seen in diabetic mice, which were associated with increased kidney inflammation and a trend toward fibrosis (Van Krieken et al., 2018). Thus, the efficacy of other SREBP inhibitors and the specific roles of SREBP in the pathogenesis of DKD and CKD remain to be investigated.

Genome-wide analysis, in vitro, and in vivo studies have demonstrated the versatility of SREBPs in mediating diverse biological processes. Particularly in the kidney, SREBP1 acts as an activator of pro-fibrotic signaling by binding to the promoter area of fibrosis-related genes, i.e., TGF $\beta$. The precise elucidation of non-lipid and direct or indirect targets of SREBPs that mediate the development of fibrosis remains a challenge. Emerging data

\section{REFERENCES}

Amemiya-Kudo, M., Shimano, H., Yoshikawa, T., Yahagi, N., Hasty, A. H., Okazaki, H., et al. (2000). Promoter analysis of the mouse sterol regulatory element-binding protein-1c gene. J. Biol. Chem. 275, 31078-31085. doi: 10. 1074/jbc.M005353200

Bengoechea-Alonso, M. T., and Ericsson, J. (2009). A phosphorylation cascade controls the degradation of active SREBP1. J. Biol. Chem. 284, 5885-5895. doi: 10.1074/jbc.M807906200

Bertolio, R., Napoletano, F., Mano, M., Maurer-Stroh, S., Fantuz, M., Zannini, A., et al. (2019). Sterol regulatory element binding protein 1 couples mechanical cues and lipid metabolism. Nat. Commun. 10:1326. doi: 10.1038/s41467-01909152-7

Besnard, V., Wert, S. E., Stahlman, M. T., Postle, A. D., Xu, Y., Ikegami, M., et al. (2009). Deletion of Scap in alveolar type II cells influences lung lipid homeostasis and identifies a compensatory role for pulmonary lipofibroblasts. J. Biol. Chem. 284, 4018-4030. doi: 10.1074/jbc.M805388200

Breyer, M. D., and Susztak, K. (2016). The next generation of therapeutics for chronic kidney disease. Nat. Rev. Drug Discov. 15, 568-588. doi: 10.1038/nrd. 2016.67

Brown, M. S., and Goldstein, J. L. (1997). The SREBP pathway: regulation of cholesterol metabolism by proteolysis of a membrane-bound transcription factor. Cell 89, 331-340. doi: 10.1016/S0092-8674(00)80213-5

Brown, M. S., and Goldstein, J. L. (2008). Selective versus total insulin resistance: a pathogenic paradox. Cell Metab. 7, 95-96. doi: 10.1016/j.cmet.2007. 12.009

Chen, G., Wang, T., Uttarwar, L., Vankrieken, R., Li, R., Chen, X., et al. (2014). SREBP-1 is a novel mediator of TGF $\beta 1$ signaling in mesangial cells. J. Mol. Cell Biol. 6, 516-530. doi: 10.1093/jmcb/mju041

Cheng, C., Ru, P., Geng, F., Liu, J., Yoo, J. Y., Wu, X., et al. (2015). Glucose-mediated N-glycosylation of SCAP is essential for SREBP-1 activation and tumor growth. Cancer Cell 28, 569-581. doi: 10.1016/j.ccell.2015. 09.021

Chung, K. W., Lee, E. K., Lee, M. K., Oh, G. T., and Yu, B. P. (2018). Impairment of PPAR $\alpha$ and the fatty acid oxidation pathway aggravates renal fibrosis during aging. J. Am. Soc. Nephrol. 29, 1223-1237. doi: 10.1681/ASN.2017070802

Cohen, J. C., Horton, J. D., and Hobbs, H. H. (2009). Human fatty liver disease: old questions and new insights. Science 332, 1519-1523. doi: 10.1126/science. 1204265

Colgan, S. M., Al-Hashimi, A. A., and Austin, R. C. (2011). Endoplasmic reticulum stress and lipid dysregulation. Expert Rev. Mol. Med. 13, 1-14. doi: 10.1017/ S1462399410001742

Das, F., Ghosh-Choudhury, N., Venkatesan, B., Li, X., Mahimainathan, L., and Choudhury, G. G. (2008). Akt kinase targets association of TGF- $\beta$ induced suggest that continued investigation of the SREBP pathway and the discovery of its small molecule inhibitors will facilitate the amelioration of kidney disease via lipid-dependent and independent pathways (Figure 7).

\section{AUTHOR CONTRIBUTIONS}

DD conceived and wrote the manuscript, and designed the figures. $\mathrm{DK}$ and $\mathrm{HH}$ provided critical revisions of the manuscript. $\mathrm{HH}$ made the final approval of the version to be published.

\section{FUNDING}

The preparation of this review was supported by grants from the Korean Health Technology R\&D Project through the Korean Health Industry Development Institute (HI18C0695).

expression of CBP with SMAD 3 to regulate plasminogen activator inhibitor-1. J. Cell. Physiol. 214, 513-527. doi: 10.1002/JCP

Doliana, R., Bot, S., Mungiguerra, G., Canton, A., Paron Cilli, S., and Colombatti, A. (2001). Isolation and characterization of EMILIN-2, a new component of the growing EMILINs family and a member of the EMI domain-containing superfamily. J. Biol. Chem. 276, 12003-12011. doi: 10.1074/jbc.M0115 91200

Dong, Q., Giorgianni, F., Deng, X., Beranova-Giorgianni, S., Park, E. A., Raghow, R., et al. (2014). Phosphorylation of sterol regulatory element binding protein1a by protein kinase A (PKA) regulates transcriptional activity. Biochem. Biophys. Res. Commun. 449, 449-454. doi: 10.1016/j.bbrc.2014.05.046

Düvel, K., Yecies, J. L., Menon, S., Raman, P., Lipovsky, A. I., Souza, A. L., et al. (2010). Activation of a metabolic gene regulatory network downstream of mTOR complex 1. Mol. Cell 39, 171-183. doi: 10.1016/j.molcel.2010.06.022

Elbadawy, M., Usui, T., Yamawaki, H., and Sasaki, K. (2018). Novel functions of death-associated protein kinases through mitogen-activated protein kinaserelated signals. Int. J. Mol. Sci. 19:E3031. doi: 10.1080/00927879708826060

Ferrari, A., Maretto, S., Girotto, D., Volpin, D., and Bressan, G. M. (2004). SREBP contributes to induction of collagen VI transcription by serum starvation. Biochem. Biophys. Res. Commun. 313, 600-605. doi: 10.1016/j.bbrc.2003.11.159

Geertz, M., and Maerkl, S. J. (2010). Experimental strategies for studying transcription factor-DNA binding specificities. Brief. Funct. Genomics 9, 362373. doi: 10.1093/bfgp/elq023

Gilardi, F., Migliavacca, E., Naldi, A., Baruchet, M., Canella, D., Le Martelot, G., et al. (2014). Genome-wide analysis of SREBP1 activity around the clock reveals its combined dependency on nutrient and circadian signals. PLoS Genet. 10:e1004155. doi: 10.1371/journal.pgen.1004155

Goldstein, J. L., DeBose-Boyd, R. A., and Brown, M. S. (2006). Protein sensors for membrane sterols. Cell 124, 35-36. doi: 10.1016/j.cell.2005.12.022

Gong, Y., Lee, J. N., Lee, P. C. W., Goldstein, J. L., Brown, M. S., and Ye, J. (2006). Sterol-regulated ubiquitination and degradation of Insig-1 creates a convergent mechanism for feedback control of cholesterol synthesis and uptake. Cell Metab. 3, 15-24. doi: 10.1016/j.cmet.2005.11.014

Grootjans, J. J., Zimmermann, P., Reekmans, G., Smets, A., Degeest, G., Dürr, J., et al. (1997). Syntenin, a PDZ protein that binds syndecan cytoplasmic domains. Proc. Natl. Acad. Sci. U.S.A. 94, 13683-13688. doi: 10.1073/pnas.94.25.13683

Guillet-Deniau, I., Pichard, A.-L., Koné, A., Esnous, C., Nieruchalski, M., Girard, J., et al. (2004). Glucose induces de novo lipogenesis in rat muscle satellite cells through a sterol-regulatory-element-binding-protein-1c-dependent pathway. J. Cell Sci. 117, 1937-1944. doi: 10.1242/jcs.01069

Ha, T.-S., Park, H.-Y., Seong, S.-B., and Ahn, H. Y. (2015). Angiotensin II induces endoplasmic reticulum stress in podocyte, which would be further augmented by PI3-kinase inhibition. Clin. Hypertens. 21:13. doi: 10.1186/s40885-0150018-5 
Han, Y., Hu, Z., Cui, A., Liu, Z., Ma, F., Xue, Y., et al. (2019). Post-translational regulation of lipogenesis via AMPK-dependent phosphorylation of insulininduced gene. Nat. Commun. 10:623. doi: 10.1038/s41467-019-08585-4

Hasty, A. H., Shimano, H., Yahagi, N., Amemiya-Kudo, M., Perrey, S., Yoshikawa, T., et al. (2000). Sterol regulatory element-binding protein-1 is regulated by glucose at the transcriptional level. J. Biol. Chem. 275, 31069-31077. doi: 10. 1074/jbc.M003335200

Herman-Edelstein, M., Scherzer, P., Tobar, A., Levi, M., and Gafter, U. (2014). Altered renal lipid metabolism and renal lipid accumulation in human diabetic nephropathy. J. Lipid Res. 55, 561-572. doi: 10.1194/jlr.P040501

Hirano, Y., Yoshida, M., Shimizu, M., and Sato, R. (2001). Direct demonstration of rapid degradation of nuclear sterol regulatory element-binding proteins by the ubiquitin-proteasome pathway. J. Biol. Chem. 276, 36431-36437. doi: 10.1074/ jbc.M105200200

Horton, J. D., Goldstein, J. L., and Brown, M. S. (2002). SREBPs: activators of the complete program of cholesterol and fatty acid synthesis in the liver. J. Clin. Invest. 109, 1125-1131. doi: 10.1172/JCI200215593

Hua, X., Yokoyama, C., Wu, J., Briggs, M. R., Brown, M. S., Goldstein, J. L., et al. (1993). SREBP-2, a second basic-helix-loop-helix-leucine zipper protein that stimulates transcription by binding to a sterol regulatory element. Proc. Natl. Acad. Sci. U.S.A. 90, 11603-11607. doi: 10.1073/pnas.90.24.11603

Huang, F., and Chen, Y.-G. (2012). Regulation of TGF- $\beta$ receptor activity. Cell Biosci. 2:9. doi: 10.1186/2045-3701-2-9

Hwangbo, C., Tae, N., Lee, S., Kim, O., Park, O., Kim, J., et al. (2016). Syntenin regulates TGF- $\beta 1$-induced Smad activation and the epithelial-tomesenchymal transition by inhibiting caveolin- mediated TGF- $\beta$ type I receptor internalization. Oncogene 35, 389-401. doi: 10.1038/onc.2015.100

Jiang, T., Liebman, S. E., Lucia, M. S., Li, J., and Levi, M. (2005a). Role of altered renal lipid metabolism and the sterol regulatory element binding proteins in the pathogenesis of age-related renal disease. Kidney Int. 68, 2608-2620. doi: 10.1111/j.1523-1755.2005.00733.x

Jiang, T., Liebman, S. E., Lucia, M. S., Phillips, C. L., and Levi, M. (2005b). Calorie restriction modulates renal expression of sterol regulatory element binding proteins, lipid accumulation, and age-related renal disease. J. Am. Soc. Nephrol. 16, 2385-2394. doi: 10.1681/ASN.2004080701

Jiang, T., Wang, Z., Proctor, G., Moskowitz, S., Liebman, S. E., Rogers, T., et al. (2005c). Diet-induced obesity in C57BL/6J mice causes increased renal lipid accumulation and glomerulosclerosis via a sterol regulatory element-binding protein-1c-dependent pathway. J. Biol. Chem. 280, 32317-32325. doi: 10.1074/ jbc.M500801200

Ju, W., Greene, C. S., Eichinger, F., Nair, V., Hodgin, J. B., Bitzer, M., et al. (2013). Defining cell-type specificity at the transcriptional level in human disease. Genome Res. 23, 1862-1873. doi: 10.1101/gr.155697.113

Jun, H., Song, Z., Chen, W., Zanhua, R., Yonghong, S., Shuxia, L., et al. (2009). In vivo and in vitro effects of SREBP-1 on diabetic renal tubular lipid accumulation and RNAi-mediated gene silencing study. Histochem. Cell Biol. 131, 327-345. doi: 10.1007/s00418-008-0528-2

Kang, H. M., Ahn, S. H., Choi, P., Ko, Y. A., Han, S. H., Chinga, F., et al. (2015). Defective fatty acid oxidation in renal tubular epithelial cells has a key role in kidney fibrosis development. Nat. Med. 21, 37-46. doi: 10.1038/nm.3762

Kim, J. B., Spotts, G. D., Halvorsen, Y.-D., Hsiu-Ming, S., Ellenberger, T., Towle, H. C., et al. (1995). Dual DNA binding specificity of ADD1/SREBP1 controlled by a single amino acid in the basic helix-loop-helix domain. Mol. Cell. Biol. 15, 2582-2588. doi: 10.1038/news.2009.50

Kishino, M., Yukawa, K., Hoshino, K., Kimura, A., Shirasawa, N., Otani, H., et al. (2004). Deletion of the kinase domain in death-associated protein kinase attenuates tubular cell apoptosis in renal ischemia-reperfusion injury. J. Am. Soc. Nephrol. 15, 1826-1834. doi: 10.1097/01.ASN.0000131527.59781.F2

Lambert, S. A., Jolma, A., Campitelli, L. F., Das, P. K., Yin, Y., Albu, M., et al. (2018). The human transcription factors. Cell 172, 650-665. doi: 10.1016/j.cell.2018. 01.029

Lan, H. Y., and Chung, A. C. K. (2012). TGF- $\beta /$ Smad signaling in kidney disease. Semin. Nephrol. 32, 236-243. doi: 10.1016/j.semnephrol.2012.04.002

Lay, S., Le Lefrère, I., Trautwein, C., Dugail, I., and Krief, S. (2002). Insulin and sterol-regulatory element-binding protein-1c (SREBP-1c) regulation of gene expression in 3T3-L1 adipocytes: identification of CCAAT/enhancer-binding protein $\beta$ as an SREBP-1c target. J. Biol. Chem. 277, 35625-35634. doi: 10.1074/ jbc.M203913200
Lee, G. Y., Jang, H., Lee, H., Huh, Y., Choi, S., Chung, J., et al. (2014). PIASymediated sumoylation of SREBP1c regulates hepatic lipid metabolism upon fasting signaling. Mol. Cell. Biol. 34, 926-938. doi: 10.1128/MCB.01166-13

Lee, S. J., Sekimoto, T., Yamashita, E., Nagoshi, E., Nakagawa, A., Imamoto, N., et al. (2003). The structure of importin- $\beta$ bound to SREBP-2: nuclear import of a transcription factor. Science 302, 1571-1576. doi: 10.1126/science.1088372

Lee, W. H., Higuchi, H., Ikeda, S., Macke, E. L., Takimoto, T., Pattnaik, B. R., et al. (2016). Mouse Tmem135 mutation reveals a mechanism involving mitochondrial dynamics that leads to age-dependent retinal pathologies. eLife 5:19264. doi: 10.7554/eLife.19264

Lewis, S. A., Takimoto, T., Mehrvar, S., Higuchi, H., Doebley, A. L., Stokes, G., et al. (2018). The effect of Tmem135 overexpression on the mouse heart. PLoS One 13:e0201986. doi: 10.1371/journal.pone.0201986

Li, H. Y., Oh, Y. S., Choi, J. W., Jung, J. Y., and Jun, H. S. (2017). Blocking lysophosphatidic acid receptor 1 signaling inhibits diabetic nephropathy in db/db mice. Kidney Int. 91, 1362-1373. doi: 10.1016/j.kint.2016.11.010

Li, J., Ananthapanyasut, W., and Yu, A. S. L. (2011). Claudins in renal physiology and disease. Pediatr. Nephrol. 26, 2133-2142. doi: 10.1007/s00467-011-1824-y

Li, Y., Xu, S., Mihaylova, M. M., Zheng, B., Hou, X., Jiang, B., et al. (2011). AMPK phosphorylates and inhibits SREBP activity to attenuate hepatic steatosis and atherosclerosis in diet-induced insulin-resistant mice. Cell Metab. 13, 376-388. doi: 10.1016/j.cmet.2011.03.009

Lin, T., Zeng, L., Liu, Y., DeFea, K., Schwartz, M. A., Chien, S., et al. (2003). Rho-ROCK-LIMK-cofilin pathway regulates shear stress activation of sterol regulatory element binding proteins. Circ. Res. 92, 1296-1304. doi: 10.1161/01. RES.0000078780.65824.8B

Liu, Y., Chen, B. P. C., Lu, M., Zhu, Y., Stemerman, M. B., Chien, S., et al. (2002). Shear stress activation of SREBP1 in endothelial cells is mediated by integrins. Arterioscler. Thromb. Vasc. Biol. 22, 76-81. doi: 10.1161/hq0102. 101822

Mongiat, M., Ligresti, G., Marastoni, S., Lorenzon, E., Doliana, R., and Colombatti, A. (2007). Regulation of the extrinsic apoptotic pathway by the extracellular matrix glycoprotein EMILIN2. Mol. Cell. Biol. 27, 7176-7187. doi: 10.1128/ MCB.00696-07

Murea, M., Freedman, B. I., Parks, J. S., Antinozzi, P. A., Elbein, S. C., and Ma, L. (2010). Lipotoxicity in diabetic nephropathy: the potential role of fatty acid oxidation. Clin. J. Am. Soc. Nephrol. 5, 2373-2379. doi: 10.2215/CJN.08160910

Mustafa, M., Wang, T. N., Chen, X., Gao, B., and Krepinsky, J. C. (2016). SREBP inhibition ameliorates renal injury after unilateral ureteral obstruction. Am. J. Physiol. Physiol. 311, F614-F625. doi: 10.1152/ajprenal.00140.2016

Na, J., Sweetwyne, M. T., Park, A. S. D., Susztak, K., and Cagan, R. L. (2015). Diet-induced podocyte dysfunction in drosophila and mammals. Cell Rep. 12, 636-647. doi: 10.1016/j.celrep.2015.06.056

Nakagawa, S., Nishihara, K., Miyata, H., Shinke, H., Tomita, E., Kajiwara, M., et al. (2015). Molecular markers of tubulointerstitial fibrosis and tubular cell damage in patients with chronic kidney disease. PLoS One 10:0136994. doi: 10.1371/journal.pone.0136994

Nakakuki, M., Kawano, H., Notsu, T., Imada, K., Mizuguchi, K., and Shimano, H. (2014). A novel processing system of sterol regulatory element-binding protein-1c regulated by polyunsaturated fatty acid. J. Biochem. 155, 301-313. doi: $10.1093 / \mathrm{jb} / \mathrm{mvu} 019$

Oki, S., Ohta, T., Shioi, G., Hatanaka, H., Ogasawara, O., Okuda, Y., et al. (2018). ChIP-Atlas: a data-mining suite powered by full integration of public ChIP-seq data. EMBO Rep. 19:e46255. doi: 10.15252/embr.201846255

Pai, J. T., Guryev, O., Brown, M. S., and Goldstein, J. L. (1998). Differential stimulation of cholesterol and unsaturated fatty acid biosynthesis in cells expressing individual nuclear sterol regulatory element-binding proteins. J. Biol. Chem. 273, 26138-26148. doi: 10.1074/jbc.273.40. 26138

Peng, F., Wu, D., Gao, B., Ingram, A. J., Zhang, B., Chorneyko, K., et al. (2008). RhoA/Rho-kinase contribute to the pathogenesis of diabetic renal disease. Diabetes Metab. Res. Rev. 57, 1683-1692. doi: 10.2337/db07-1149

Peterson, T. R., Sengupta, S. S., Harris, T. E., Carmack, A. E., Kang, S. A., Balderas, E., et al. (2011). mTOR complex 1 regulates lipin 1 localization to control the SREBP pathway. Cell 146, 408-420. doi: 10.1016/j.cell.2011. 06.034

Plantier, L., Besnard, V., Xu, Y., Ikegami, M., Wert, S. E., Hunt, A. N., et al. (2012). Activation of sterol-response element-binding proteins (SREBP) in alveolar 
type II cells enhances lipogenesis causing pulmonary lipotoxicity. J. Biol. Chem. 287, 10099-10114. doi: 10.1074/jbc.M111.303669

Proctor, G., Jiang, T., Iwahashi, M., Wang, Z., Li, J., and Levi, M. (2006). Regulation of renal fatty acid and cholesterol metabolism, inflammation, and fibrosis in Akita and OVE26 mice with type 1 diabetes. Diabetes Metab. Res. Rev. 55, 2502-2509. doi: 10.2337/db05-0603

Rendon-Huerta, E., Chavarria-Velazquez, C., and Montaño, L. (2013). Claudins, inflammation and epithelial-mesenchymal transition in gastric tissue. J. Gastrointest. Dig. Syst. 3:4. doi: 10.4172/2161-069X.1000149

Romagnani, P., Remuzzi, G., Glassock, R., Levin, A., Tonelli, M., Massy, Z., et al. (2017). Chronic kidney disease. Nat. Rev. Dis. Prim. 23:17088. doi: 10.1038/ nrdp. 2017.88

Saito, K., Ishizaka, N., Hara, M., Matsuzaki, G., Sata, M., Mori, I., et al. (2005). Lipid accumulation and transforming growth factor- $\beta$ upregulation in the kidneys of rats administered angiotensin II. Hypertension 46, 1180-1185. doi: 10.1161/01. HYP.0000184653.75036.d5

Sanchez-Alvarez, M., Finger, F., Del Mar Arias-Garcia, M., Bousgouni, V., PascualVargas, P., and Bakal, C. (2014). Signaling networks converge on TORC1SREBP activity to promote endoplasmic reticulum homeostasis. PLoS One 9:0101164. doi: 10.1371/journal.pone.0101164

Schlingmann, B., Molina, S. A., and Koval, M. (2015). Claudins: gatekeepers of lung epithelial function. Semin. Cell Dev. Biol. 42, 47-57. doi: 10.1016/j.semcdb.2015. 04.009

Seo, Y., Kim, H., Infante, A. M., Im, S., Xie, X., and Osborne, T. F. (2009). Genomewide analysis of SREBP-1 binding in mouse liver chromatin reveals a preference for promoter proximal binding to a new motif. Proc. Natl. Acad. Sci. U.S.A. 106, 13765-13769. doi: 10.1073/pnas.0904246106

Shimano, H. (2001). Sterol regulatory element-binding proteins (SREBPs) as regulators of lipid metabolism. Prog. Lipid Res. 40, 439-452. doi: 10.1016/s0163$7827(01) 00010-8$

Shimano, H., Horton, J. D., Shimomura, I., Hammer, R. E., Brown, M. S., and Goldstein, J. L. (1997). Isoform 1c of sterol regulatory element binding protein is less active than isoform 1a in livers of transgenic mice and in cultured cells. J. Clin. Invest. 99, 846-856. doi: 10.1172/JCI119248

Shimano, H., and Sato, R. (2017). SREBP-regulated lipid metabolism: convergent physiology-divergent pathophysiology. Nat. Rev. Endocrinol. 13, 710-730. doi: 10.1038/nrendo.2017.91

Shimomura, I., Bashmakov, Y., and Horton, J. D. (1999a). Increased levels of nuclear SREBP-1c associated with fatty livers in two mouse models of diabetes mellitus. J. Biol. Chem. 274, 30028-30032. doi: 10.1074/jbc.274.42.30028

Shimomura, I., Bashmakov, Y., Ikemoto, S., Horton, J. D., Brown, M. S., and Goldstein, J. L. (1999b). Insulin selectively increases SREBP-1c mRNA in the livers of rats with streptozotocin-induced diabetes. Proc. Natl. Acad. Sci. U.S.A. 96, 13656-13661. doi: 10.1073/pnas.96.24.13656

Shimomura, I., Matsuda, M., Hammer, R. E., Bashmakov, Y., Brown, M. S., and Goldstein, J. L. (2000). Decreased IRS-2 and increased SREBP-1c lead to mixed insulin resistance and sensitivity in livers of lipodystrophic and ob/ob mice. Mol. Cell 6, 77-86. doi: 10.1016/S1097-2765(05)00010-9

Simon, N., and Hertig, A. (2015). Alteration of fatty acid oxidation in tubular epithelial cells: from acute kidney injury to renal fibrogenesis. Front. Med. 2:52. doi: 10.3389/fmed.2015.00052

Sterzel, R. B., Hartner, A., Schlötzer-Schrehardt, U., Voit, S., Hausknecht, B., Doliana, R., et al. (2000). Elastic fiber proteins in the glomerular mesangium in vivo and in cell culture. Kidney Int. 58, 1588-1602. doi: 10.1046/j.1523- 1755. 2000.00320.x

Sun, H., Yuan, Y., and Sun, Z. L. (2013). Cholesterol contributes to diabetic nephropathy through SCAP-SREBP-2 pathway. Int. J. Endocrinol. 2013:592576. doi: $10.1155 / 2013 / 592576$

Sun, L., Halaihel, N., Zhang, W., Rogers, H., and Levi, M. (2002). Role of sterol regulatory element-binding protein 1 in regulation of renal lipid metabolism and glomerulosclerosis in diabetes mellitus. J. Biol. Chem. 277, 18919-18927. doi: 10.1074/jbc.M110650200

Sun, L. P., Li, L., Goldstein, J. L., and Brown, M. S. (2005). Insig required for sterolmediated inhibition of Scap/SREBP binding to COPII proteins in vitro. J. Biol. Chem. 280, 26483-26490. doi: 10.1074/jbc.M504041200

Sureshbabu, A., Muhsin, S. A., and Choi, M. E. (2016). TGF- $\beta$ signaling in the kidney: profibrotic and protective effects. Am. J. Physiol. Ren. Physiol. 310, F596-F606. doi: 10.1152/ajprenal.00365.2015
Toth, J. I., Datta, S., Athanikar, J. N., Freedman, L. P., and Osborne, T. F. (2004). Selective coactivator interactions in gene activation by SREBP1a and -1c. Mol. Cell. Biol. 24, 8288-8300. doi: 10.1128/MCB.24.18. 8288

Uttarwar, L., Gao, B., Ingram, A. J., and Krepinsky, J. C. (2012). SREBP-1 activation by glucose mediates TGF- $\beta$ upregulation in mesangial cells. Am. J. Physiol. Ren. Physiol. 302, F329-F341. doi: 10.1152/ajprenal.00136.2011

Van Krieken, R., Chen, G., Gao, B., Read, J., Al Saleh, H. A., Li, R., et al. (2017). Sterol regulatory element binding protein (SREBP)-1 is a novel regulator of the transforming growth factor (TGF) $-\beta$ receptor I (T $\beta R I)$ through exosomal secretion. Cell. Signal. 29, 158-167. doi: 10.1016/j.cellsig.2016. 11.004

Van Krieken, R., Marway, M., Parthasarathy, P., Mehta, N., Ingram, A., Gao, B., et al. (2018). Inhibition of SREBP with fatostatin does not attenuate early diabetic nephropathy in male mice. Endocrinology 159, 1479-1495. doi: 10 1210/en.2018-00093

Wang, J., Wen, Y., Lv, L. L., Liu, H., Tang, R. N., Ma, K. L., et al. (2015). Involvement of endoplasmic reticulum stress in angiotensin II-induced NLRP3 inflammasome activation in human renal proximal tubular cells in vitro. Acta Pharmacol. Sin. 36, 821-830. doi: 10.1038/aps.2015.21

Wang, T. N., Chen, X., Li, R., Gao, B., Mohammed-Ali, Z., Lu, C., et al. (2015). SREBP-1 mediates angiotensin II-induced TGF- $\beta 1$ upregulation and glomerular fibrosis. J. Am. Soc. Nephrol. 26, 1839-1854. doi: 10.1681/ASN 2013121332

Wang, Z., Jiang, T., Li, J., Proctor, G., McManaman, J. L., Lucia, S., et al. (2005). Regulation of renal lipid metabolism, lipid accumulation, and glomerulosclerosis in FVBdb/db mice with type 2 diabetes. Diabetes Metab. Res. Rev. 54, 2328-2335. doi: 10.2337/diabetes.54.8.2328

Watanabe, M., Houten, S. M., Wang, L., Moschetta, A., Mangelsdorf, D. J., Heyman, R. A., et al. (2004). Bile acids lower triglyceride levels via a pathway involving FXR. SHP, and SREBP-1c. J. Clin. Invest. 113, 1408-1418. doi: 10. $1172 /$ JCI2 1025

Watanabe, M., and Uesugi, M. (2013). Small-molecule inhibitors of SREBP activation-potential for new treatment of metabolic disorders. Medchemcomm 4, 1422-1433. doi: 10.1039/c3md00177f

Webster, A. C., Nagler, E. V., Morton, R. L., and Masson, P. (2017). Chronic kidney disease. Lancet 389, 1238-1252. doi: 10.1016/S0140-6736(16)32 064-5

Woroniecka, K. I., Park, A. S. D., Mohtat, D., Thomas, D. B., Pullman, J. M., and Susztak, K. (2011). Transcriptome analysis of human diabetic kidney disease. Diabetes Metab. Res. Rev. 60, 2354-2369. doi: 10.2337/db101181

Wu, D., Peng, F., Zhang, B., Ingram, A. J., Gao, B., and Krepinsky, J. C. (2007) Collagen I induction by high glucose levels is mediated by epidermal growth factor receptor and phosphoinositide 3-kinase/Akt signalling in mesangial cells. Diabetologia 50, 2008-2018. doi: 10.1007/s00125-007-0721-1

Wu, D., Peng, F., Zhang, B., Ingram, A. J., Kelly, D. J., Gilbert, R. E., et al. (2009). PKC- $\beta 1$ mediates glucose-induced Akt activation and TGF- $\beta 1$ upregulation in mesangial cells. J. Am. Soc. Nephrol. 20, 554-566. doi: 10.1681/ASN. 2008040445

Wu, X., Romero, D., Swiatek, W. I., Dorweiler, I., Kikani, C. K., Sabic, H., et al. (2014). PAS kinase drives lipogenesis through SREBP-1 maturation. Cell Rep. 8, 242-255. doi: 10.1016/j.celrep.2014.06.006

Yabe, D., Brown, M. S., and Goldstein, J. L. (2002). Insig-2, a second endoplasmic reticulum protein that binds SCAP and blocks export of sterol regulatory element-binding proteins. Proc. Natl. Acad. Sci. U.S.A. 99, 12753-12758. doi: 10.1073/pnas.162488899

Yang, T., Espenshade, P. J., Wright, M. E., Yabe, D., Gong, Y., Aebersold, R., et al. (2002). Crucial step in cholesterol homeostasis: sterols promote binding of SCAP to INSIG-1, a membrane protein that facilitates retention of SREBPs in ER. Cell 110, 489-500. doi: 10.1016/s0092-8674(02)00872-3

Ye, J., Dave, U., Grishin, N., Goldstein, J., and Brown, M. (2000). Asparagineproline sequence within membrane-spanning segment of SREBP triggers intramembrane cleavage by site-2 protease. Proc. Natl. Acad. Sci. U.S.A. 97, 5123-5128. doi: 10.1073/pnas.97.10.5123

Yellaturu, C. R., Deng, X., Park, E. A., Raghow, R., and Elam, M. B. (2009). Insulin enhances the biogenesis of nuclear sterol regulatory element-binding protein (SREBP)-1c by posttranscriptional down-regulation of Insig-2A and 
its dissociation from SREBP cleavage-activating protein (SCAP).SREBP1c complex. J. Biol. Chem. 284, 31726-31734. doi: 10.1074/jbc.M109. 050914

Yoshikawa, T., Shimano, H., Amemiya-Kudo, M., Yahagi, N., Hasty, A. H., Matsuzaka, T., et al. (2001). Identification of liver X receptor-retinoid X receptor as an activator of the sterol regulatory element-binding protein 1c gene promoter. Mol. Cell. Biol. 21, 2991-3000. doi: 10.1128/MCB.21.9. 2991

Yu, A. S. L. (2015). Claudins and the kidney. J. Am. Soc. Nephrol. 26, 11-19. doi: 10.1681/ASN.2014030284

Zhang, M.-Z., Wang, X., Yang, H., Fogo, A. B., Murphy, B. J., Kaltenbach, R., et al. (2017). Lysophosphatidic acid receptor antagonism protects against diabetic nephropathy in a type 2 diabetic model. J. Am. Soc. Nephrol. 28, 3300-3311. doi: 10.1681/ASN.2017010107
Zhao, X., Ji, J., Yang, F., Zhao, X., Feng, D., Wang, Q., et al. (2012). Regulation of lipogenesis by cyclin-dependent kinase 8 - mediated control of SREBP-1. J. Clin. Invest. 122, 2417-2427. doi: 10.1172/JCI61462

Conflict of Interest: The authors declare that the research was conducted in the absence of any commercial or financial relationships that could be construed as a potential conflict of interest.

Copyright (c) 2020 Dorotea, Koya and Ha. This is an open-access article distributed under the terms of the Creative Commons Attribution License (CC BY). The use, distribution or reproduction in other forums is permitted, provided the original author(s) and the copyright owner(s) are credited and that the original publication in this journal is cited, in accordance with accepted academic practice. No use, distribution or reproduction is permitted which does not comply with these terms. 


\section{APPENDIX}

Abbreviations: ABHD6, abhydrolase domain containing 6; ACACA, acetyl-Coa carboxylase alpha; ACAT, acetyl-Coa acetyltransferase; ACC, acetyl-CoA carboxylase; ACLY, ATP citrate lyase; ACOX, acyl-CoA oxidase; ACS, acetyl-CoA synthetase; ACSL, acyl-CoA synthetase long-chain family member; ACSS, acyl-CoA synthetase short-chain family member; ADIPOR2, adiponectin receptor; AIDA, axin interactor, dorsalization associated; AMPK, AMP-activated protein kinase; Ang II, angiotensin II; AT1, angiotensin II type 1; BROX BRO1, domain and CAAX motif containing; CBP, CREBbinding protein; CDK8, cyclin-dependent kinase 8; ChIP, chromatin immunoprecipitation; CKD, chronic kidney disease; CLCN4, chloride voltage-gated channel 4; CLDN34D, claudin 34D; COL, collagen; CPT, carnitine palmitoyltransferase; CTGF, connective tissue growth factor; CYP51A1, cytochrome P450 family 51 subfamily A member 1; DAPK3, deathassociated protein kinase 3; DHCR7, 7-dehydrocholesterol reductase; DHFR, dihydrofolate reductase; DKD, diabetic kidney disease; ECM, extracellular matrix; EEF2, eukaryotic translation elongation factor 2; EMILIN2, elastin microfibril interfacer 2; EMT, epithelial-to-mesenchymal transition; ER, endoplasmic reticulum; FADS2, fatty acid desaturase; FAO, fatty acid oxidation; FAS, fatty acid synthase; FDFT1, farnesyl diphosphate farnesyl transferase; FDPS, farnesyl diphosphate synthase; FOXK2, forkhead box K2; FXR, farnesoid x receptor; GARR, growth arrest-responsive region; GM11213, predicted gene 11213; GPAT, glycerol-3-phosphate acyltransferase; GSK, glycogen synthase kinase; HG, high glucose; HMGCR, 3hydroxy-3-methylglutaryl-Coa reductase; HMGCS, 3-hydroxy3-methylglutaryl-CoA synthase; $\mathrm{HNF} 4 \alpha$, hepatocyte nuclear factor-4 $\alpha$; HSD17B, hydroxysteroid 17-beta dehydrogenase;
IDI1, isopentenyl-diphosphate delta isomerase; IL31RA, interleukin 31 receptor A; INSIG, insulin-induced gene; KPNA1, karyopherin subunit alpha 1; LDLR, LDL receptor; LPA, lysophosphatidic acid; LSS, lanosterol synthase; LXR, liver X receptor; LXRE LXR-responsive elements; MBLAC2, metallobeta-lactamase domain containing 2; MC, mesangial cell; MEF, mouse embryonic fibroblast; MRPS15, mitochondrial ribosomal protein S1; MSH3, MutS homolog; MSMO1, methylsterol monooxygenase; mTORC1, mammalian target of rapamycin complex 1; MT-RNR2L, MT-RNR2 like; MVD, mevalonate diphosphate decarboxylase; MVK, mevalonate kinase; PAI1, plasminogen activator inhibitor 1; PANK3, pantothenate kinase; PCSK9, proprotein convertase subtilisin/kexin type 9; PDP2, pyruvate dehydrogenase phosphatase catalytic subunit 2; PGC1 $\alpha$, proliferator-activated receptor-gamma coactivator 1; PGK1, phosphoglycerate kinase 1; PI3K, phosphatidylinositol 3-kinase; PKA, protein kinase A; PLA2G6, phospholipase A2 group 6; POLR3G, RNA polymerase 3 subunit G; PPAR, peroxisome proliferator-activated receptor; PUFAs, polyunsaturated fatty acids; S1P, site-1 protease; S2P, site-2 protease; SCAP, SREBP cleavage-activating protein; SCD, stearoyl-CoA desaturase; SDCBP2, syndecan binding protein; SFI1, SFI1 centrin binding protein; SIRT1, sirtuin 1; SLCO4C1, solute carrier organic anion transporter family member 4C1; SOD2, superoxide dismutase; SORBS1, sorbin and SH3 domain containing 1; SQLE, squalene epoxidase; SRE, sterol response element; SREBF, sterol regulatory element-binding transcription factor; SREBP, sterol regulatory element-binding protein; SSPN, sarcospan; STARD4, StAR-related lipid transfer domain containing; TAAR, trace amine-associated receptor; TC, total cholesterol; TG, triglyceride; TGF $\beta$, transforming growth factor $\beta$; TMEM, transmembrane protein; TSC1/2, tuberous sclerosis complex $1 / 2$; T $\beta$ RI, TGF $\beta$ receptor I; WDR74, WD repeat domain 74 . 